ARTICLE

\title{
Turning main-group element magnesium into a highly active electrocatalyst for oxygen reduction reaction
}

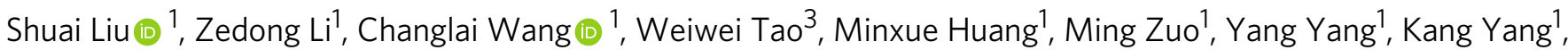
Lijuan Zhang ${ }^{4}$, Shi Chen ${ }^{1}{ }^{1}$, Pengping $X u^{1} \&$ Qianwang Chen ${ }^{1,2 凶}$

It is known that the main-group metals and their related materials show poor catalytic activity due to a broadened single resonance derived from the interaction of valence orbitals of adsorbates with the broad sp-band of main-group metals. However, Mg cofactors existing in enzymes are extremely active in biochemical reactions. Our density function theory calculations reveal that the catalytic activity of the main-group metals $(\mathrm{Mg}, \mathrm{Al}$ and $\mathrm{Ca}$ ) in oxygen reduction reaction is severely hampered by the tight-bonding of active centers with hydroxyl group intermediate, while the $\mathrm{Mg}$ atom coordinated to two nitrogen atoms has the nearoptimal adsorption strength with intermediate oxygen species by the rise of p-band center position compared to other coordination environments. We experimentally demonstrate that the atomically dispersed $\mathrm{Mg}$ cofactors incorporated within graphene framework exhibits a strikingly high half-wave potential of $910 \mathrm{mV}$ in alkaline media, turning a s/p-band metal into a highly active electrocatalyst.

\footnotetext{
${ }^{1}$ Hefei National Laboratory for Physical Science at Microscale and Department of Materials Science \& Engineering, University of Science and Technology of China, Hefei 230026, China. ${ }^{2}$ Anhui Province Key Laboratory of Condensed Matter Physics at Extreme Conditions, High Magnetic Field Laboratory of Chinese, Academy of Sciences, Hefei 230031, China. ${ }^{3}$ Department of Mechanical Engineering, Boston University, Boston, MA 02215, USA. ${ }^{4}$ Shanghai Synchrotron Radiation Facility, Shanghai Institute of Applied Physics, Shanghai 201203, China. ${ }^{\circledR}$ email: cqw@ustc.edu.cn
} 
E ectrochemical energy conversion is promising for meeting growing energy demand and to reduce environmental pollution from traditional catalysts ${ }^{1,2}$, thus electrocatalysis is a topic that is gaining interest. High-performance and cost-efficient electrocatalysts are of great importance to energy conversion processes. The development of renewable energy technologies, such as polymer electrolyte membrane fuel cell (PEMFC) and metal-air batteries via the oxygen reduction reaction (ORR), are heavily dependent on the improvement of highly active electrocatalysts ${ }^{3}$.

In the past decades, the d-band center model proposed by Hammer and Nørskov has been widely applied in understanding and predicting catalytic activity on transition metal-based electrocatalysts ${ }^{4-6}$. A single parameter, the center position of $\mathrm{d}$ band $\left(\varepsilon_{\mathrm{d}}\right)$, is linearly related to the adsorption free energies of adsorbates on transition metal surface ${ }^{7}$. An optimal d-band structure with moderate adsorption strength is essential in catalyst design, which can be demonstrated by the volcano-type activity plots 8,9 . More specifically, the interaction between the adsorbate states and the metal d-states gives rise to a deep-lying filled bonding state and a partially filled anti-bonding state. The adsorption strength is given by the filling of the anti-bonding state, a neither too strong nor too weak bonding is in favor of catalysis ${ }^{10,11}$. For a more in-depth description, the lower $\varepsilon_{\mathrm{d}}$ down from Fermi level is, the lower resultant anti-bonding level will be (increased occupancy), which leads to a weaker adsorption ${ }^{12}$. For instance, Stamenkovic et al. realized a high ORR catalytic activity for $\mathrm{Pt}_{3} \mathrm{Ni}$ alloy by turning the electronic structure of surface $\mathrm{Pt}$ atoms into a lower d-band center position ${ }^{13}$. With increased occupancy of anti-bonding state of $\mathrm{OH}^{*}$, weaker adsorption is induced on $\mathrm{Pt}_{3} \mathrm{Ni}$ surface $\left(\Delta G_{\mathrm{OH} *}\right.$, which is closer to volcano-type center), therefore the activity of $\mathrm{Pt}_{3} \mathrm{Ni}$ becomes higher than pure $\mathrm{Pt}$ catalyst.

On the contrary, main group metals, such as $\mathrm{Mg}$ and $\mathrm{Al}$ are thought to be catalytic inactive ${ }^{14}$ due to lacking the combination of empty and filled host-orbitals that is crucial for electronic processes involved in elementary steps in catalytic cycles ${ }^{15}$, especially for ORR process involving multi oxygenated intermediates transformation. However, no one has ever set foot into this virgin land.

Different from a narrow d-band for transition metals, main group metals sites with a delocalized s/p-band as the host-orbital mainly broadens the adsorbate state due to "weak chemsorption" 7,11 . The interaction of adsorbates guest-states with those unbefitting surface-states results in too strong adsorption (deep and filled resonance state makes adsorption site poisoned) or too weak adsorption (makes no activation of adsorbates). To the best of our knowledge, main group metals serving as active catalytic sites during electrocatalytic reaction has not been reported so far. However, in nature, enzymes containing the magnesium $(\mathrm{Mg})$ cofactors have key roles in many vital metabolic pathways and nucleic acid biochemistry ${ }^{16}$, for example, $\mathrm{Mg}$ isocitrate in isocitrate lyase ${ }^{17}$. Typically, $\mathrm{Mg}^{2+}$ in cofactor has a suitable affinity for oxygenated species, so the cofactor can function as a Lewis acid for the activation of Mg-bound water to a hydroxide ion or transfer of a phosphate intermediate from one compound to another ${ }^{16}$. For instance, $\mathrm{Mg}^{2+}$-bound DNA and RNA polymerases are efficient as they participate in neutralization of the polyanionic charge of the nucleic acid for especially suitable affinity to oxygen atoms $s^{18,19}$.

The catalytic activity for ORR is strongly related to the adsorption strength of oxygen-bearing intermediates $\left(\mathrm{O}^{*}, \mathrm{OH}^{*}\right.$, and $\left.\mathrm{OOH}^{\star}\right)$ at catalytic sites ${ }^{8,20}$. As mentioned above, the $\mathrm{Mg}$ cofactor with suitable adsorption strength to oxygenated species could be favorable for ORR if its p-electronic state is tuned to a reasonable level. Direct mimicking the $\mathrm{Mg}$ cofactors configuration to design catalysts is not applicable due to their instability in experimental environment when the complex protein-based substrate does not exist ${ }^{21}$. Indeed, the intrinsic activity of catalytic sites is strongly correlated with their electronic states which can be tuned by altering the coordination number of the sites ${ }^{22}$. The previous theoretical calculation shows that surface p-state of $\mathrm{Mg}$ atom can be altered by nitrogen-heterocyclic molecules like porphyrins via $\mathrm{Mg}-\mathrm{N}$ covalent bonding ${ }^{23-25}$. This interaction can change p-orbital electrons occupancy of $\mathrm{Mg}$ site, which shifts the energy levels of the highest occupied molecular orbital (HOMO) ${ }^{25,26}$. Thus, a reasonable p-band energy level of $\mathrm{Mg}$ atom can be tuned by changing coordination environments, making $\mathrm{Mg}$ site active to catalyze oxygenated species transformation in ORR ${ }^{27}$.

In this work, graphene-based $\mathrm{N}$-coordinated metal cofactors centered with main group metals, $\mathrm{Mg}, \mathrm{Ca}$, and $\mathrm{Al}$ were investigated by both density function theory (DFT) simulations and experimental studies. The variation trends of the p-band centers of the main group metals cofactors and key intermediates adsorption strength on metals sites are well established. It is proved that the p-band center of Mg shifts upward, the adsorption strength of oxygenated species decrease, which is contrary to the trend observed in d-band metals. It indicates that the catalytic activity of main group metal $\mathrm{Mg}$ can be tuned by coordination with two $\mathrm{N}$ atoms changing its local $\mathrm{N}$-coordination, which derived from the modulation of p-band filling and then influences ORR catalytic activity. The single $\mathrm{Mg}$ atom catalysts shows extremely high ORR activity, which surpasses the performance of commercial $\mathrm{Pt} / \mathrm{C}$ in alkaline conditions and far exceeds that of most transition metal-based catalysts reported so far.

\section{Results}

Calculation of electrocatalytic activity. DFT simulations were performed using Vienna Ab Initio Simulation Package (VASP) ${ }^{28,29}$ to study the possible catalytic activity and reaction mechanism in ORR. Three types of metal atoms ( $\mathrm{Mg}, \mathrm{Ca}$, and $\mathrm{Al})$ coordinated with different numbers (from 1 to 4 ) of pyridine nitrogen atoms are confined in a graphene matrix (Fig. 1a and Supplementary Fig. 1) which is denoted as $\mathrm{M}$ (C or A) $\mathrm{N}_{\mathrm{x}} \mathrm{C}$ according to $\mathrm{N}$ coordination numbers. Alkaline electrolyte, commonly used in a typical ORR experiment for $\mathrm{N}$-coordinated metal moieties, is chosen to evaluate the ORR performance ${ }^{10,30}$. The free energy diagram for ideal ORR catalyst model is illustrated in Supplementary Fig. 2. The equilibrium potential is set to be $1.23 \mathrm{~V}$ versus reversible hydrogen electrode (RHE) (according to Nernst equation, for each step in ORR process with $4.92 \mathrm{~V} / 4=1.23 \mathrm{~V}$ vs. RHE), where the reaction free energies for all electron-transfer steps are zero for the ideal model when onset potential equals to equilibrium potential.

As a benchmark, the free energy diagram of commercial Pt/C is also calculated using the Pt (111) model, which is a widely used theoretical model for Pt. As shown in Supplementary Fig. 3, when the output potential is set to zero relative to RHE, ORR happens spontaneously for Pt (111) since all electron-transfer steps are exergonic. However, when the output potential increases over $0.83 \mathrm{~V}$, the free energy of one of the electron-transfer step (the last step here) becomes positive, while other steps remain negative, which indicates that the onset potential for Pt (111) is $0.83 \mathrm{~V}$.

The onset potential $\left(U_{\mathrm{RHE}}^{\mathrm{ons}}\right)$, output potential for starting of spontaneous ORR process, is determined by the reaction free energy of each electron-transfer step or adsorbate strengths of the reaction intermediates $\left(\mathrm{OOH}^{*}, \mathrm{O}^{*}, \mathrm{OH}^{*}\right)$. The optimized configurations for adsorbates at metal cofactors $\left(\mathrm{OOH}^{*}, \mathrm{O}^{*}\right.$, and $\mathrm{OH}^{*}$ ) are given in Supplementary Figs. 4-6. The free energy diagram for all models with output potential of $0,0.83$, and $1.23 \mathrm{~V}$ are drawn in Supplementary Figs. 7-9. It reveals that $\mathrm{O}_{2}$ 


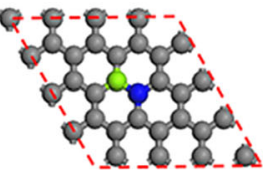

b

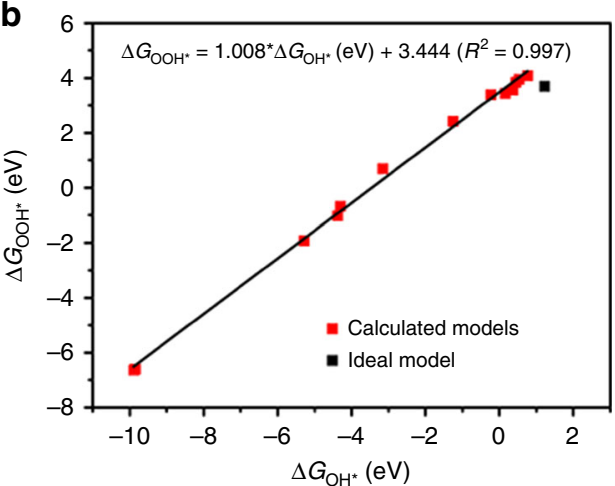

d

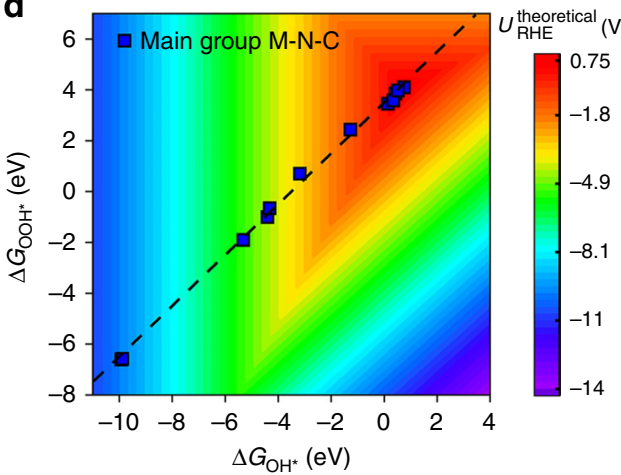

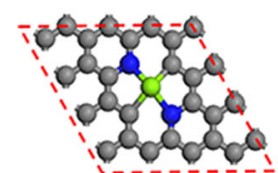
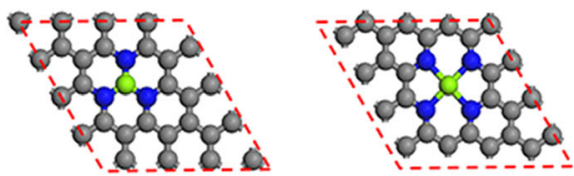

C
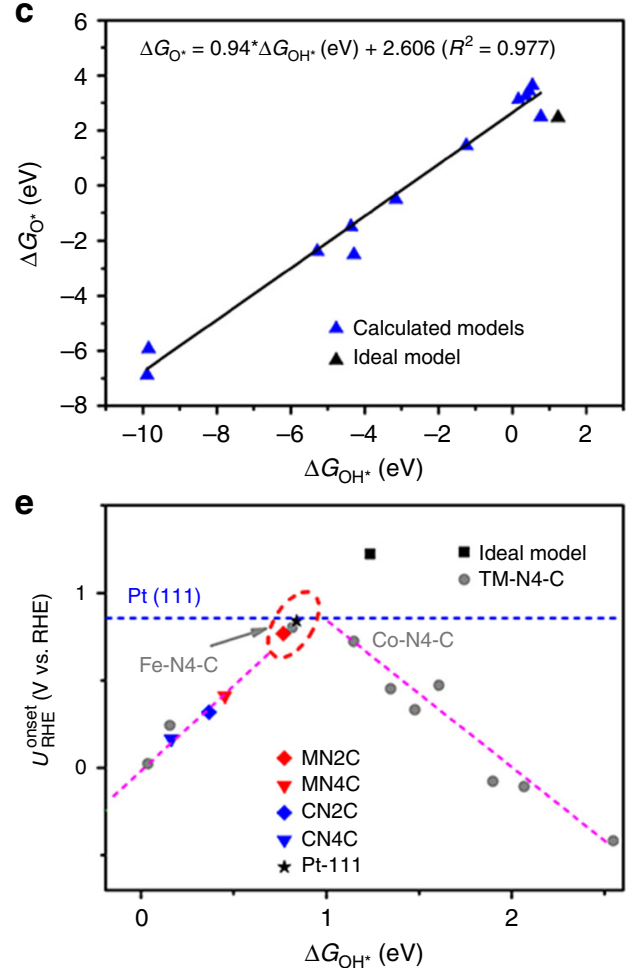

Fig. 1 The calculation models and results. a The geometric configurations of $\mathrm{Mg}$ embedded in graphene framework predominantly existing as single atoms coordinated with different numbers (from 1 to 4 ) of nitrogen atoms. The green, blue, and gray balls represent metal, $\mathrm{N}$ and $\mathrm{C}$ atoms, respectively. b Adsorption free energies of $\mathrm{OOH}$ as a function of that of $\mathrm{OH}$ for models of $\mathrm{Mg}$, $\mathrm{Al}$, and $\mathrm{Ca}$ coordinated with different numbers of pyridine nitrogen atoms embedded in graphene matrix. c Adsorption free energies of $\mathrm{O}$ versus that of $\mathrm{OH}$ for all models. $\mathbf{d}$ The two-dimensional volcano map about theoretical onset potential versus adsorption free energies $\Delta \mathrm{G}_{\mathrm{OH}^{\star}}$ and $\Delta \mathrm{G}_{\mathrm{OOH}^{*}}$ on main group metal cofactors (M-N-C). e The zoomed-in view of the onset potential versus $\Delta G_{\mathrm{OH}^{\star}}$ in the region close to the performance ceiling of models and transition metal cofactors (TM-N4-C).

transform to $\mathrm{OOH}$ radical at $\mathrm{Mg}$ and $\mathrm{Al}$ sites are exothermic but $\mathrm{OH}^{*}$ adsorption strength at $\mathrm{Al}$ and $\mathrm{Ca}$ sites are too stronger than $\mathrm{Mg}$ sites and thus induce large energy barrier in elementary steps, so only $\mathrm{Mg}$ sites show better ORR performance.

Adsorption-activity relationships. According to previous definition $^{28}$, the ORR electrocatalytic performance can be predicted by intermediates adsorption energy. Therefore, it's important to identify their relationship so as to help the design of electrocatalysts. The reaction free energies for each step and the adsorption free energies of adsorbates for all three different metal-centered catalysts with various $\mathrm{N}$ neighbors are listed in Supplementary Tables $1-3$. Figure $1 \mathrm{~b}, \mathrm{c}$ plot the absorption free energy for $\mathrm{OOH}^{*}$ and $\mathrm{O}^{*}$ as a function of that for $\mathrm{OH}^{\star}$. All data have a linear relationship that can be fitted by:

$$
\begin{gathered}
\Delta G_{\mathrm{OOH} *}=1.008 \times \Delta G_{\mathrm{OH} *}+3.444\left(R^{2}=0.997\right) \\
\Delta G_{\mathrm{O} *}=0.94 \times \Delta G_{\mathrm{OH} *}+2.606\left(R^{2}=0.977\right)
\end{gathered}
$$

which is consistent with reported linear relationship existing in transition metal based catalysts $20,31,32$. According to those equations, $\Delta G_{\mathrm{OH} *}$ is chosen to be the only independent variable to describe $U_{\mathrm{RHE}}^{\text {onset }}$ in all models ${ }^{33}$.

The onset potentials for each model are listed in Supplementary Tables $4-5$. Figure $1 \mathrm{~d}$ plots the $U_{\mathrm{RHE}}^{\text {onset }}$ volcano map as a function of $\Delta G_{\mathrm{OH} *}$ and $\Delta G_{\mathrm{OOH} *}$. The $U_{\mathrm{RHE}}^{\text {onset }}$ for all $\mathrm{Mg}, \mathrm{Al}$, and Ca-centered catalysts linear located at the left side of the volcano map where $\Delta G_{\mathrm{OH} *}$ is less than $1 \mathrm{eV}$. It indicates that the badly strong binding of $\mathrm{OH}^{*}$ severely hampers their ORR process as the unbefitting host-levels of most metal sites. Thus $U_{\mathrm{RHE}}^{\text {onset }}$ of most models are far away from the volcanic map top, in other words, they show bad ORR performance. However, a few dots located near the volcano map top and Fig. 1e shows the zoomed-in view where $\Delta G_{\mathrm{OH} *}$ ranges from 0 to $2 \mathrm{~V}$. For comparison, the data points of transition metal-nitrogen-carbon (TM-N-C) models are plotted according to values reported by $\mathrm{Xu}$ et al. ${ }^{10}$. Different from both sides location for TM-N4-C models, main group metal-centered models are located at left side indicating stronger hydroxyl adsorption strength. However, interestingly, the data point of M2NC model is located near the top of the volcano map. The onset potential of $\mathrm{MN} 2 \mathrm{C}$ is $0.77 \mathrm{~V}$, which is comparable to the $U_{\mathrm{RHE}}^{\text {onset }}$ of Pt $(111)(0.83 \mathrm{~V})$ under alkaline conditions and much higher than that of $\mathrm{Al}$ and $\mathrm{Ca}$ cofactors. The $\mathrm{MN} 2 \mathrm{C}$ with moderate oxygenated species adsorption strength close to volcano top may be catalytic active.

Relationship between adsorbate strength and p-state feature. Figure 1 illustrates that the ORR performance of a metal center changes with different local coordination environments, e.g., $\mathrm{MN} 2 \mathrm{C}$ exhibits higher ORR activity compared to that of MN3C 

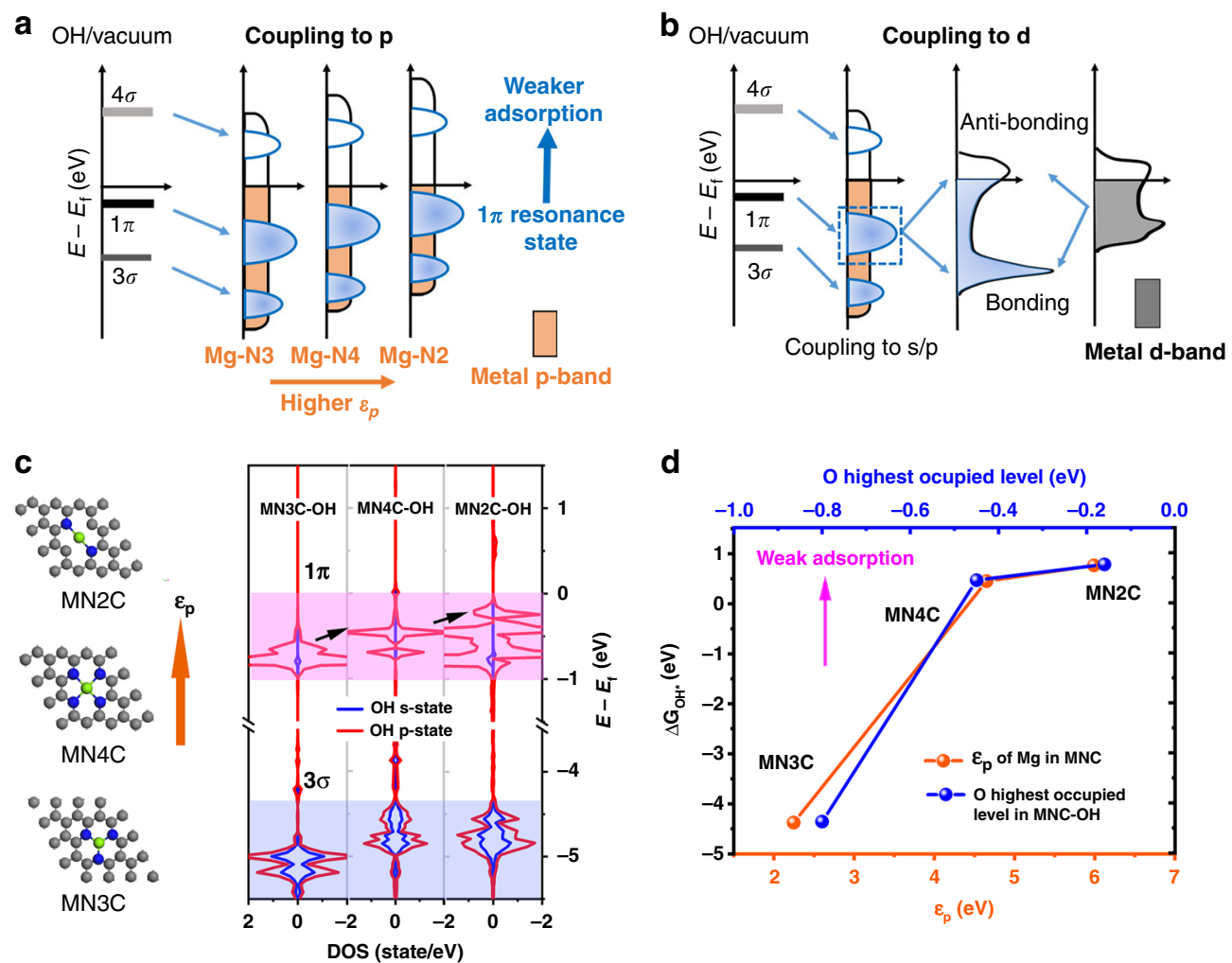

d

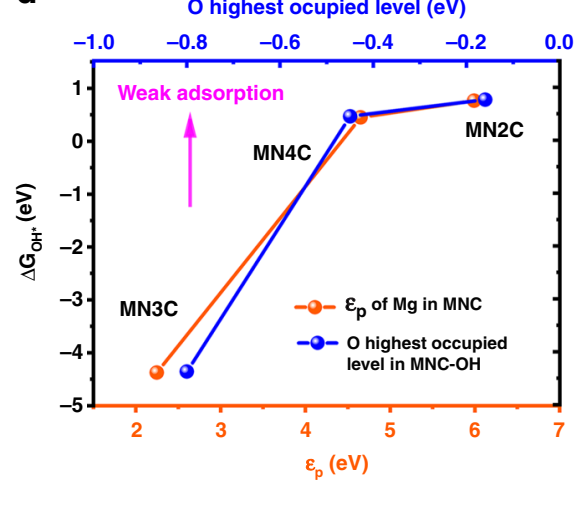

Fig. $\mathbf{2} \mathbf{O H}^{\star}$ Adsorption-energy-based activity descriptors for $\mathbf{p}$-band $\mathbf{M g}$ cofactors. $\mathbf{a}$, b Schematic illustration of the change in local electronic structure at $\mathrm{OH}$ molecular orbitals upon adsorption on the surface of $\mathrm{p}$-band metal or d-band metal. c The $\mathrm{Mg}$ cofactors' geometries in different $\mathrm{N}$-coordinated environments which tune $\varepsilon_{\mathrm{p}}$ of $\mathrm{Mg}$ atoms, and the corresponding density of states changes of $\mathrm{OH}$ after interaction with p-state of $\mathrm{Mg}$. d Adsorption free energies of $\mathrm{OH}$ as a function of the $\varepsilon_{\mathrm{p}}$ position of metal atoms for $\mathrm{Mg}$ cofactors, and also as a function of highest $\mathrm{O}$ occupied state of hydroxyl after interaction. Lines are used to fit the linear relationship.

and MN4C due to the near optimal adsorption strength with intermediate $\mathrm{OH}$ species. However, the mechanism is unknown. In order to understand the change of $\mathrm{OH}^{*}$ adsorbate strength with different coordination environment, density of states (DOS) for MNxC models are examined ( $\mathrm{x}$ from 2 to 4 and MN1C is excluded since it is not stable as shown in Supplementary Fig. 4).

It should be noted that there is difference in adsorbate-surface interaction when adsorbate interacts with a broad s/p-band or a narrow d-band. The Newns-Anderson-Grimley model can well describe this change ${ }^{34,35}$. As illustrated in Fig. 2a, when $\mathrm{OH}$ vacuum states interact with broad p-band, they are shifted down due to the interaction and broadened into resonances. The $1 \pi$ (from lone pair $\mathrm{O} 2 \mathrm{p}_{\mathrm{x}, \mathrm{y}}$ electrons) and $3 \sigma$ (from $\left.\mathrm{H} 1 \mathrm{~s}-\mathrm{O} 2 \mathrm{p}_{\mathrm{z}}\right)^{36,37}$ are renormalized. The energy level near the Fermi level is responsible to the binding strength. With higher p-band location (higher p-band center position $\left(\varepsilon_{\mathrm{p}}\right)$ ), take $\mathrm{Mg}-\mathrm{N} 2$ as example, the $1 \pi$ resonance state after interaction is closer to Fermi level, which results in weaker adsorption strength. In comparison, as illustrated in Fig. $2 b$ when interacts with d-band metals, the $\mathrm{OH}$ vacuum states are first down shifted and broadened by $\mathrm{s} / \mathrm{p}$ state, whereas subsequent coupling to $\mathrm{d}$-state gives rise to the splitting of state. The binding strength is correlated with the filling of anti-bonding state near Fermi surface.

The model is helpful to understand the adsorption difference. Here, it is found that the coordination environment changes the electrons filling of $3 \mathrm{p}$ orbital of $\mathrm{Mg}$ centers after hybridization. The combination of partially filled and extra empty p-orbitals is described as p-band center position $\left(\varepsilon_{\mathrm{p}}\right)$ of $\mathrm{Mg}$ sites (see Supplementary Table 6 and Supplementary Fig. 10). As shown in Fig. $2 c$, the $\mathrm{MN} 2 \mathrm{C}$ processes the highest $\varepsilon_{\mathrm{p}}$ compared to others., after interaction with $\mathrm{Mg}$ site, the p-adsorbate resonance state at $\mathrm{OH}$ molecular (especially $1 \pi$ ) in local DOS is higher (as shown in Fig. 2c with black arrows), which means weak adsorption strength. This trend is tabulated in Fig. $2 \mathrm{~d}$. The MN2C with the highest $\varepsilon_{\mathrm{p}}$ of $\mathrm{Mg}$ atom processes the weakest $\mathrm{OH}$ adsorption than others (as shown with orange dots), which is due to the highest interacted $1 \pi$ occupied state (as shown with blue dots).

This trend is also found in $\mathrm{Al}$ and $\mathrm{Ca}$ cofactors as shown in Supplementary Fig. 11. So MN2C with suitable p-state tuned by coordination can also bring similar adsorption strength like $\mathrm{d}$ band metals.

The synthesis of graphene-based N-coordinated Mg cofactors. In addition, Fig. 3a shows the preparation scheme of graphenebased $\mathrm{Mg}$-centered cofactor catalyst $\mathrm{Mg}-\mathrm{N}-\mathrm{C}$. It is prepared by direct pyrolysis of $\mathrm{Mg}$-based metal-organic-framework (MOF) (named as Mg-HMT) and then acid pickling. Most of $\mathrm{Mg}$ is evaporated after pyrolysis except for some of them are bonded with surrounding atoms in graphene carbon matrix (see Supplementary Information 1.2 part). Acid pickling is performed to get rid of possible impurity and finally the $\mathrm{Mg}-\mathrm{N}-\mathrm{C}$ is synthesized. The details are discussed in section 1.2 in Supplementary Information.

As shown in Supplementary Fig. 17d, e, the X-ray diffraction pattern (XRD) and the Raman spectra reveal that the catalyst is composed of defect-rich graphitic carbon. The high resolution transmission electron microscopy (HRTEM) image of $\mathrm{Mg}-\mathrm{N}-\mathrm{C}$ in Fig. $3 \mathrm{~b}$ confirms that $\mathrm{Mg}-\mathrm{N}-\mathrm{C}$ is the porous graphitic carbon. 
a
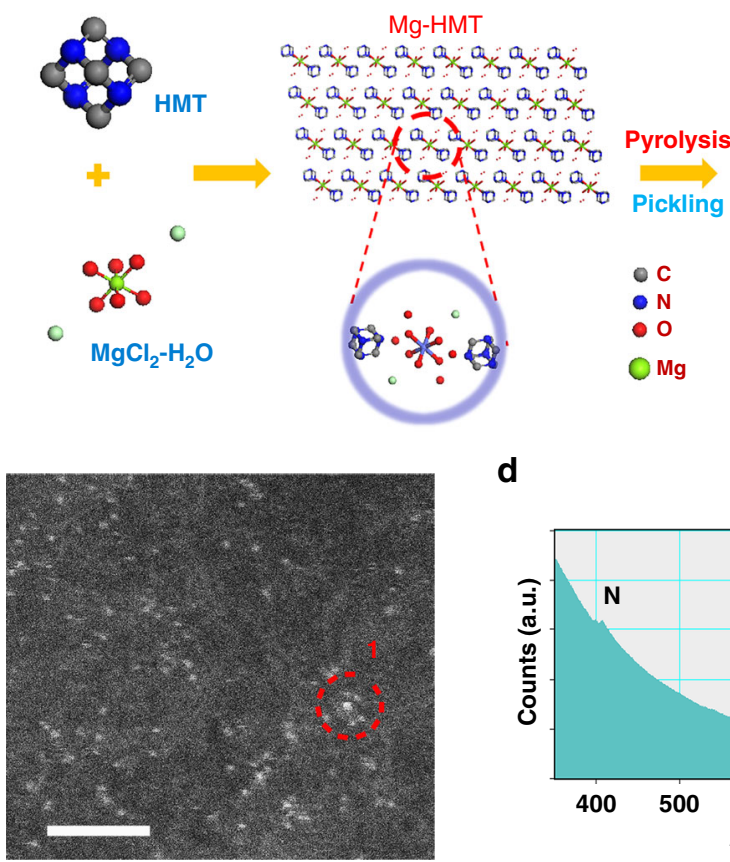

$\mathbf{f}$

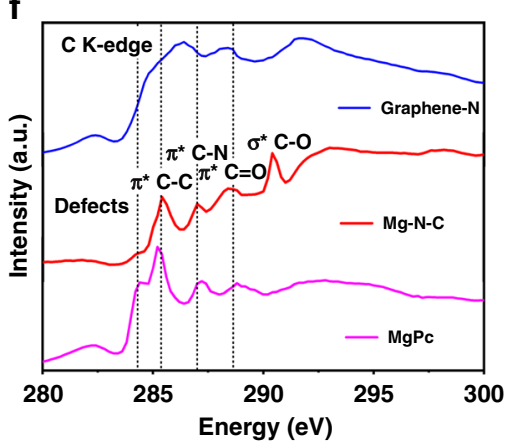

d
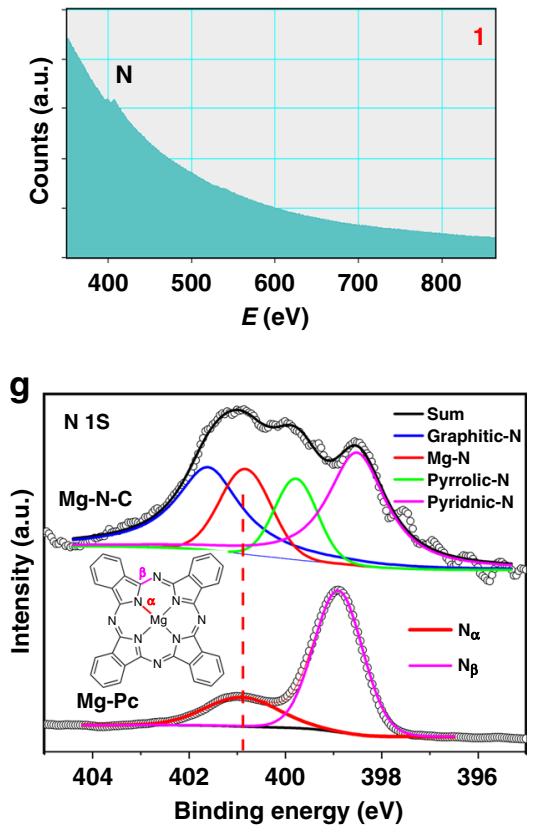

b

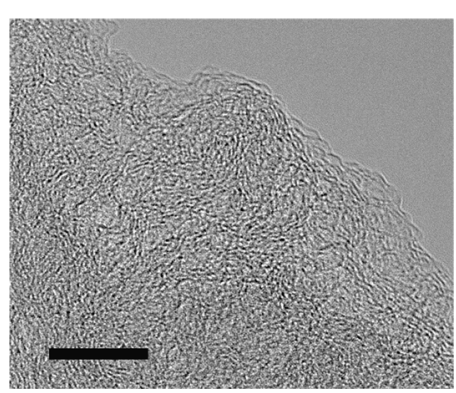

e
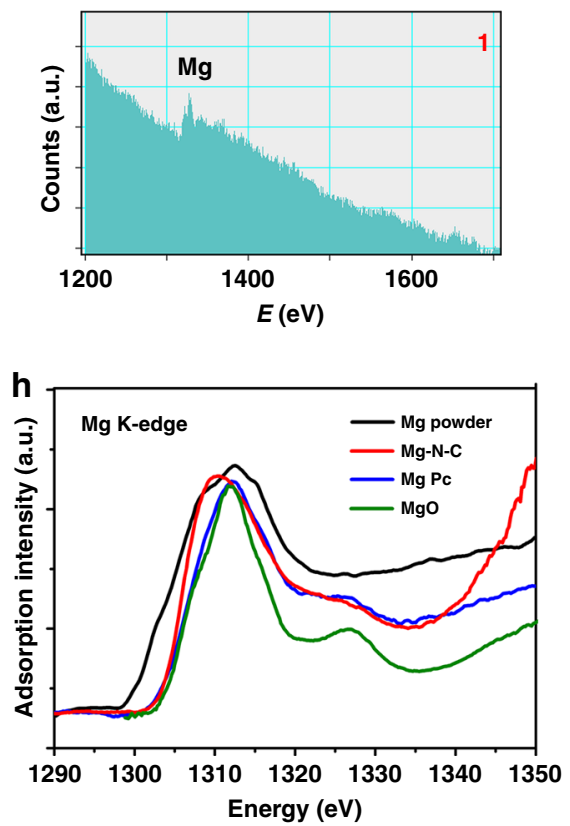

Fig. 3 The synthesis and characterization of $\mathbf{M g}-\mathbf{N}-\mathbf{C}$. a Schematic illustration of the synthesis procedure of $\mathrm{Mg}-\mathrm{N}-\mathrm{C}$. The red dash circles at $\mathrm{Mg}-\mathrm{N}-\mathrm{C}$ represents the active centers. b High resolution transmission electron microscopy (HRTEM) of Mg-N-C. Scale bar: $5 \mathrm{~nm}$. c High-angle annular dark-fieldscanning transmission electron microscopy (HAADF-STEM) image of $\mathrm{Mg}-\mathrm{N}-\mathrm{C}$. Scale bar: $2 \mathrm{~nm}$. The bright dots are Mg atoms, which can be confirmed by electron energy loss spectroscopy (EELS) spectra in $\mathbf{d}$, e, probe resolution is $0.15 \mathrm{~nm}$. $\mathbf{d}$, e The EELS spectrum for atomic site highlighted by red circle in c. f C K-edge XANES spectrum of Graphene-N, Mg-N-C and MgPc. $\mathbf{g}$ The XPS result of the $\mathrm{N}$ 1s spectrum for Mg-N-C and MgPc. $\mathbf{h}$ The XANES of Mg K-edge for samples.

High-angle annular dark-field atomic-resolution scanning transition electron microscopy (HAADF-STEM) images in Fig. $3 \mathrm{c}$ and Supplementary Fig. 21 reveal that there is large amount of atomic dispersed metal atoms (the bright dots) anchored in $\mathrm{Mg}-\mathrm{N}-\mathrm{C}$. Electron energy loss spectroscopy (EELS) spectrums in Fig. 3d, e indicate that the bright dot in Fig. $3 \mathrm{c}$ at site 1 is corresponding to $\mathrm{Mg}-\mathrm{N}_{\mathrm{x}}$ moieties. The Energy dispersive X-ray spectroscopy (EDS) images in Supplementary Fig. 17f shows that the elements of $\mathrm{Mg}, \mathrm{N}$, and $\mathrm{C}$ are uniformly distributed in $\mathrm{Mg}-\mathrm{N}-\mathrm{C}$. The $\mathrm{Mg}$ content in $\mathrm{Mg}-\mathrm{N}-\mathrm{C}$ is up to $1.32 \mathrm{wt} \%$ as determined by the inductively coupled plasma atomic emission spectroscopy (ICPAES) analysis, and no extrinsic $\mathrm{Fe}, \mathrm{Co}, \mathrm{Ni}$ is detected (below 0.01 wt\%) (Supplementary Table 8).

The valence states of elements in $\mathrm{Mg}-\mathrm{N}-\mathrm{C}$ are investigated. $\mathrm{X}$ ray absorption near-edge structure (XANES) in Fig. $3 \mathrm{f}$ reveals the catalyst is composed by heteroatoms modified carbon. The X-ray photoelectron spectroscopy (XPS) spectrum of $\mathrm{N} 1 \mathrm{~s}$ in Fig. $3 \mathrm{~g}$ can be deconvoluted into four peaks corresponding to pyridinic- $N$, pyrrolic-N, Mg-Nx (corresponding to $\mathrm{N}_{a}^{38}$ of $\mathrm{MgPc}$ which bonds with $\mathrm{Mg}$ ) and graphitic-N, respectively ${ }^{30,39}$. The $\mathrm{Mg} 1$ s and $2 \mathrm{p}$ spectrum in Supplementary Fig. 22 reveals a +2 oxidation state of $\mathrm{Mg}$ and it can be deconvoluted into $\mathrm{Mg}-\mathrm{N}$ and $\mathrm{Mg}-\mathrm{C}$ bond, no $\mathrm{Mg}-\mathrm{O}$ signal is detected. The coordination of $\mathrm{Mg}$ center in the catalyst is then further detected by XANES as can be seen in Fig. 3h. There is no obvious signal for metallic $\mathrm{Mg}$ at $\sim 1304 \mathrm{eV}$ in $\mathrm{Mg}-\mathrm{N}-\mathrm{C}$ sample, which agrees with the HAADF and EELS analysis results that most $\mathrm{Mg}$ are atomic bonded with nitrogen. The shape of absorption curve of $\mathrm{Mg}-\mathrm{N}-\mathrm{C}$ is distinct from those of $\mathrm{Mg}$ powder and $\mathrm{MgO}$, while similar to that of $\mathrm{Mg}$ phthalocyanine $(\mathrm{MgPc})$, which indicates that the valance state of $\mathrm{Mg}$ is between the metallic state $(0)$ and oxidation state $(+2)$. Note that most $\mathrm{Mg}$-compounds including magnesium nitrides, oxides, and carbides (if they are not detected before pickling) will be removed after acid pickling. Thus only the macrocyclic structures, such as $\mathrm{MgPc}$ analogs composed by heat treatment remain in the final product ${ }^{40,41}$. Moreover, the edge spectrum of magnesium is sensitive to coordination number $(\mathrm{CN})$, and the first resonance of K-edge at low energy which is related to the transitions from 1s to empty p states, will shift to lower energy as the $\mathrm{CN}$ decreases ${ }^{42-44}$. As shown in Fig. $3 \mathrm{~h}$, since the edge of 
a
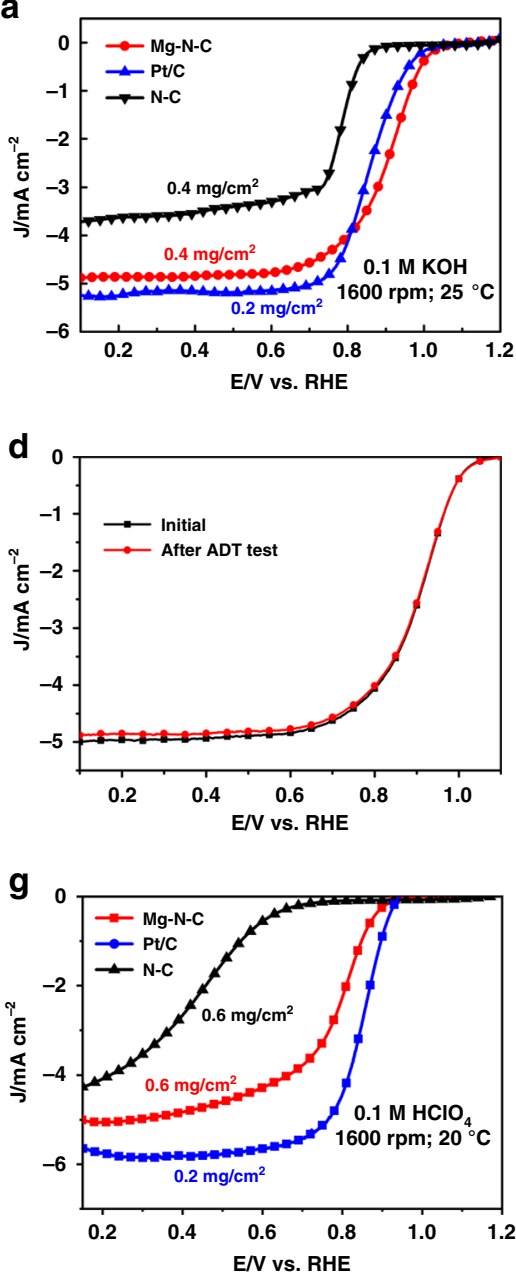
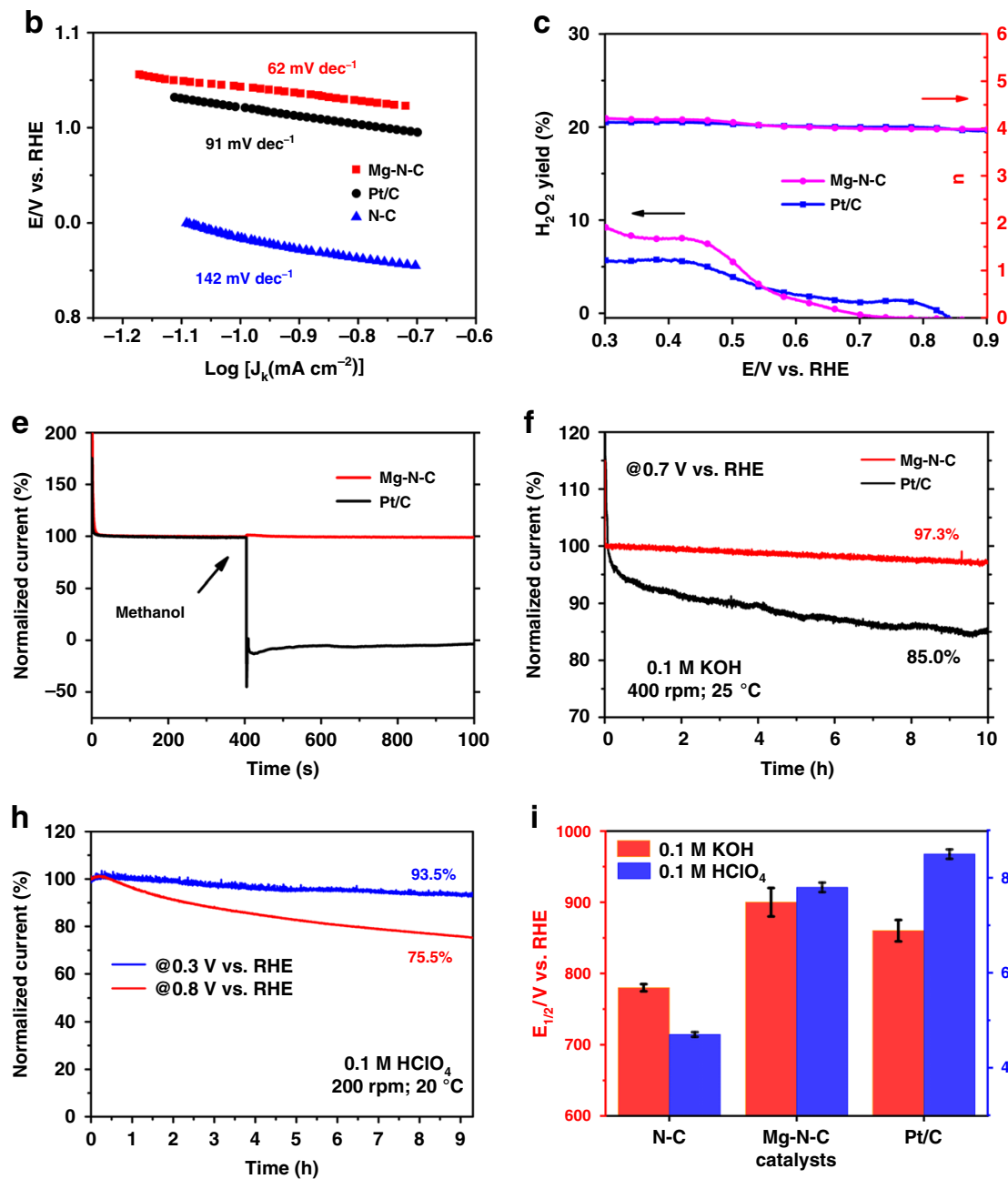

i

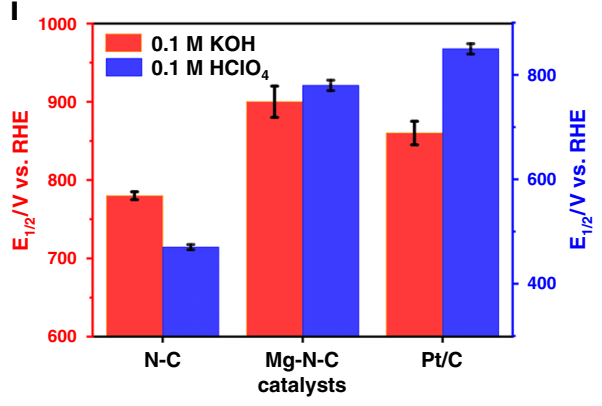

Fig. 4 Performance of $\mathbf{M g}-\mathbf{N}-\mathbf{C}$ as an oxygen reduction reaction catalyst. a $\mathrm{LSV}$ curves after normalization by glass carbon (GC) electrode in $\mathrm{O}_{2}{ }^{-}$ saturated $0.1 \mathrm{M}$ aqueous $\mathrm{KOH}$ electrolyte solutions at a sweep rate of $5 \mathrm{mV} \mathrm{s}^{-1}$. b Tafel slope of the catalysts in $0.1 \mathrm{M} \mathrm{KOH}$ solution. $\mathbf{c}$ The $\mathrm{H}_{2} \mathrm{O}_{2}$ yield and

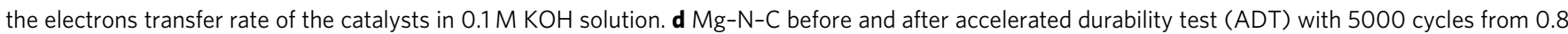
to $1.1 \mathrm{~V}$ (vs. RHE) at a sweep rate of $100 \mathrm{mV} \mathrm{s}^{-1}$. e Methanol tolerance test of $\mathrm{Mg}-\mathrm{N}-\mathrm{C}$ at $0.8 \mathrm{~V}$ (vs. RHE) with $1600 \mathrm{rpm}$ in $\mathrm{O}_{2}$-saturated $0.1 \mathrm{M} \mathrm{KOH}$ solution. $4 \mathrm{ml}$ methanol is injected into $110 \mathrm{ml} \mathrm{O}$-saturated $0.1 \mathrm{M} \mathrm{KOH}$ solution at $400 \mathrm{~s}$. $\mathrm{f} \mathrm{CA}$ test of the catalysts at $0.7 \mathrm{~V}$ (vs. RHE) with $400 \mathrm{rpm}$ for $10 \mathrm{~h}$ in $\mathrm{O}_{2}$-saturated $0.1 \mathrm{M} \mathrm{KOH}$ solution. $\mathbf{g} \mathrm{LSV}$ curves after normalization by glass carbon (GC) electrode in $\mathrm{O}_{2}$-saturated $0.1 \mathrm{M}^{2}$ aqueous $\mathrm{HClO}_{4}$ electrolyte solution at a sweep rate of $10 \mathrm{mV} \mathrm{s} \mathrm{s}^{-1}$. h CA test of $\mathrm{Mg}-\mathrm{N}-\mathrm{C}$ in $0.1 \mathrm{M} \mathrm{HClO}$ solution. $\mathbf{i} E_{1 / 2}$ for different catalysts in both alkaline and acidic solutions.

$\mathrm{Mg}-\mathrm{N}-\mathrm{C}$ is left shifted comparing to that of $\mathrm{MgPc}(\mathrm{CN}=4)$, the number of $\mathrm{CN}$ should be less than 4 in $\mathrm{Mg}-\mathrm{N}-\mathrm{C}$. Furthermore, according to DFT simulations, MN1C is an unstable cofactor and the activity of $\mathrm{MN} 3 \mathrm{C}$ is too poor to catalyze ORR. Thus, the results of DFT and XANES for $\mathrm{Mg}-\mathrm{N}-\mathrm{C}$ indicate that the most likely high active moiety in $\mathrm{Mg}-\mathrm{N}-\mathrm{C}$ is the $\mathrm{MN} 2 \mathrm{C}$ cofactor (the different spatial configurations similar to MN2C like isomer and edge-bonded moieties are compared in Supplementary Figs. 39-41).

The ORR activity of $\mathrm{Mg}-\mathrm{N}-\mathrm{C}$ is then investigated in both basic and acidic environments with a rotating disk electrode (RDE). For comparison, the ORR performance of nitrogen-doped graphene $(\mathrm{N}-\mathrm{C})$ and commercial $20 \mathrm{wt} \% \mathrm{Pt} / \mathrm{C}$ are also tested. Figure 4a shows the linear sweep voltammetry (LSV) curve after normalization by glass carbon (GC) electrodes in $\mathrm{O}_{2}$-saturated $0.1 \mathrm{M}$ aqueous $\mathrm{KOH}$ solutions. The $\mathrm{Mg}-\mathrm{N}-\mathrm{C}$ shows excellent ORR activity with half-wave potential $\left(E_{1 / 2}\right)$ of $910 \mathrm{mV}$ and onset potential $\left(E_{\text {onset }}\right)$ of $1.03 \mathrm{~V}$. The $E_{1 / 2}$ of $\mathrm{Mg}-\mathrm{N}-\mathrm{C}$ surpasses the value of $780 \mathrm{mV}$ for $\mathrm{N}-\mathrm{C}$ and is higher than that of $860 \mathrm{mV}$ for commercial $\mathrm{Pt} / \mathrm{C}$. The outstanding ORR activity is further confirmed by the smaller Tafel slope of $\mathrm{Mg}-\mathrm{N}-\mathrm{C}$ with a value of $62 \mathrm{mV} \mathrm{dec}^{-1}$ as compared to that of $91 \mathrm{mV} \mathrm{dec}^{-1}$ for $\mathrm{Pt} / \mathrm{C}$ and $142 \mathrm{mV} \mathrm{dec}^{-1}$ for $\mathrm{N}-\mathrm{C}$ as shown in Fig. 4b. It indicates that the first electron transfer $\left(59 \mathrm{mV} \mathrm{dec}{ }^{-1}\right)$ catalyzed by $\mathrm{Mg}-\mathrm{N}-\mathrm{C}$ is probably the rate-determining step. The electrochemical impedance spectroscopy (EIS) diagram in Supplementary Fig. 23 shows smaller impedance of $\mathrm{Mg}-\mathrm{N}-\mathrm{C}$ as comparing to $\mathrm{Pt} / \mathrm{C}$. According to the rotating ring disk electrode (RRDE) test result shown in Fig. 4c, the electron-transfer rate for $\mathrm{Mg}-\mathrm{N}-\mathrm{C}$ is close to 4 , similar to that of $\mathrm{Pt} / \mathrm{C}$. The $\mathrm{H}_{2} \mathrm{O}_{2}$ yield is approximated to be zero at $0.8 \mathrm{~V}$, which proves the existence of a $4 \mathrm{e}^{-}$associative pathway for $\mathrm{Mg}-\mathrm{N}-\mathrm{C}$ in ORR (it's also confirmed by $\mathrm{RDE}$ voltammograms at various rotation rates in Supplementary Fig. 24). Accelerated durability test (ADT) is cycled in $\mathrm{O}_{2}$ saturated $0.1 \mathrm{M} \mathrm{KOH}$ to test the durability. As shown in Fig. 4d, after 5000 cycles, negligible change in $E_{1 / 2}$ is observed, indicating the high stability of catalyst. According to chronoamperometry (CA) measurements in Fig. 4e, after injecting methanol into the solution, significant drop in the current density for $\mathrm{Pt} / \mathrm{C}$ is observed, while $\mathrm{Mg}-\mathrm{N}-\mathrm{C}$ shows excellent tolerance to methanol crossover. Moreover, $97.3 \%$ normalized current is retained at $0.7 \mathrm{~V}$ (RHE) after $10 \mathrm{~h}$ durability test for $\mathrm{Mg}-\mathrm{N}-\mathrm{C}$ as can be seen 
in Fig. 4f, while only $85.0 \%$ normalized current is retained for $\mathrm{Pt} /$ $\mathrm{C}$, which also indicates great stability of the $\mathrm{Mg}-\mathrm{N}-\mathrm{C}$ catalyst.

The ORR activity of $\mathrm{Mg}-\mathrm{N}-\mathrm{C}$ in acidic condition is also evaluated. In contrast to the poor activity of most metal-free nitrogen-doped carbon-based catalysts in acidic condition ${ }^{45,46}$, $\mathrm{Mg}-\mathrm{N}-\mathrm{C}$ shows excellent performance with $E_{1 / 2}$ up to $790 \mathrm{mV}$ in $0.1 \mathrm{M} \mathrm{HClO}_{4}$ as shown in Fig. 4g. High ORR stability is also observed in Fig. 4h. The activity of $\mathrm{Mg}-\mathrm{N}-\mathrm{C}$ with different loading is shown in Supplementary Fig. 25. Figure 4i summarizes the ORR performance of all three catalysts, indicating that $\mathrm{Mg}-\mathrm{N}-\mathrm{C}$ is close to that of $\mathrm{Pt} / \mathrm{C}$ in acidic media while surpasses that of $\mathrm{Pt} / \mathrm{C}$ in alkaline condition. A comparison of the ORR activity summarized in Supplementary Table 9 between $\mathrm{Mg}-\mathrm{N}-\mathrm{C}$ and other transition metal based catalysts reported so far shows that it even exceeds the ORR activity of most non Fe-based catalysts. Furthermore, when $\mathrm{Mg}-\mathrm{N}-\mathrm{C}$ is used to build zinc-air batteries, it shows dramatic stability under steady discharge at current density of $20 \mathrm{~mA} \mathrm{~cm}^{-2}$ for $8 \mathrm{~h}$ as can be seen in Supplementary Fig. 26. Ca-HMT and Al-HMT are also synthesized and tested. Consistent with the DFT simulations, the ORR activity of these pyrolysis products are much less active than $\mathrm{Mg}-\mathrm{N}-\mathrm{C}$ as shown in Supplementary Fig. 27.

According to DFT simulations and experimental results, we conclude that $\mathrm{Mg}-\mathrm{N}-\mathrm{C}$ shows outstanding ORR performance which is comparable to $\mathrm{Pt} / \mathrm{C}$ and some transition metals. In order to find out the active site in $\mathrm{Mg}-\mathrm{N}-\mathrm{C}$ corresponding to the catalytic activity, in Supplementary Fig. 29, we explore its activity contribution from high electrochemical surface area (ECSA) and evaluate its activity by high kinetic current density $\left(J_{\mathrm{k}}\right)$. Supplementary Fig. 30 shows that impurity of amorphous oxide before acid pickling is not the active mass since the ORR activity is enhanced after etching treatment. A poisoning experiment is then performed by employing KSCN to block the M-Nx sites ${ }^{47-}$ 49. As shown in Supplementary Fig. 31, the $E_{1 / 2}$ with negative shifts by $109 \mathrm{mV}$ due to the poisoning effect indicates that $\mathrm{Mg}-\mathrm{N}$ moiety is the active site in ORR.

The $\mathrm{Mg}$ content in $\mathrm{Mg}-\mathrm{N}-\mathrm{C}$ is about $1.3 \mathrm{wt} \%$ and the ratio of $\mathrm{Mg}-\mathrm{N}$ is hard to be varied due to the constant $\mathrm{Mg}$ ratio in metalligand in MOFs precursor. To test the influence of $\mathrm{Mg}$ doping content on catalytic activity, another experiment is designed to vary $\mathrm{Mg}$ content in nitrogen doped carbon $(\mathrm{N}-\mathrm{C})$ host $^{50}$. The detailed synthesis process is described in Supplementary Information. According to Supplementary Fig. 32, after heat treatment, the ORR activity in both acidic and basic electrolytes are improved with increasing $\mathrm{Mg}(+2)$ contents. Structure characterization in Supplementary Figs. 33-36, confirms that the increasing content of $\mathrm{Mg}(+2)$ cooperated with $\mathrm{N}$-doped carbon matrix, but neither the $\mathrm{N}$-doping nor modified carbon, is responsible for activity enhancement. These results confirm that it is the $\mathrm{Mg}-\mathrm{N}$ moiety corresponding to the high ORR activity of $\mathrm{Mg}-\mathrm{N}-\mathrm{C}$.

We then further explore the possible reaction pathway of $\mathrm{MN} 2 \mathrm{C}$ in ORR. The initial adsorbed sites are set at $\mathrm{Mg}, \mathrm{N}, \mathrm{C} 1$ adjacent $\mathrm{N}$ and C2 away from N (labeled MN2C-M, MN2C-N, MN2C-C1, and $\mathrm{MN} 2 \mathrm{C}-\mathrm{C} 2$, respectively). Supplementary Fig. 37 shows that adsorbates would all move to the $\mathrm{Mg}$ sites for the final stable structures, which confirms the $\mathrm{Mg}$ sites are the preferred stable adsorbate sites of these models. The free energy diagram of different models as can be seen in Fig. 5a indicates that the most energetic optimized catalytic site is MN2C-C1, where the rate determine step (RDS) is $\mathrm{OOH}^{\star}$ formation step with the lowest energy barrier value of $0.41 \mathrm{eV}$ in case of $1.23 \mathrm{~V}$ output potential (thus leads to the highest value of $U_{\mathrm{RHE}}^{\mathrm{onset}}=1.23 \mathrm{~V}-0.41 \mathrm{~V}=0.82 \mathrm{~V}$ ). The reaction pathway of MN2C-C1 are shown in Fig. 5b i-v. Notable, $\mathrm{O}^{*}$ is adsorbed to both $\mathrm{Mg}$ and $\mathrm{C} 1$ as shown in Fig. 5b iv, which reveals

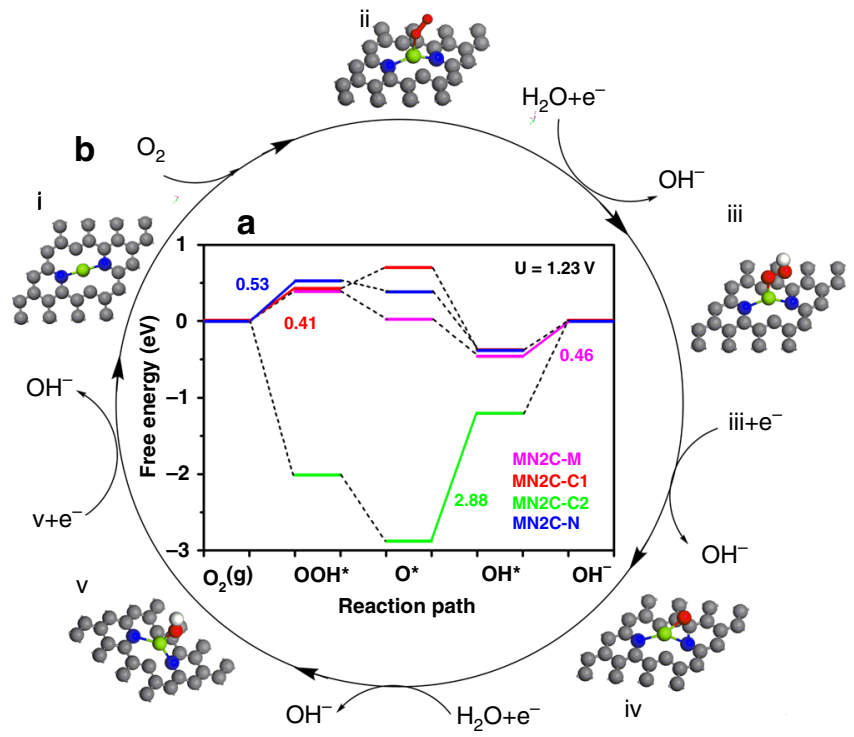

Fig. 5 The free energy diagram of $\mathrm{MN2C}$ and its possible reaction pathway. a The free energy diagram of MN2C at different optimized adsorbed reaction sites at $1.23 \mathrm{~V}$ and the full oblique lines and corresponding value shows the RDS and energy barriers of catalysts. b Favorable reaction pathway of $\mathrm{MN} 2 \mathrm{C}$. And the active sites are $\mathrm{Mg}$ and $\mathrm{C1}$ atoms. Green, blue, red, white and gray balls represent metal, $\mathrm{N}, \mathrm{O}, \mathrm{H}$, and $\mathrm{C}$ atoms, respectively. Specially, the $\mathrm{O}^{*}$ is adsorbed at both $\mathrm{Mg}$ and $\mathrm{C} 1$ adjacent to $\mathrm{N}$ atoms in (iv).

that the dual catalytic sites in $\mathrm{MN} 2 \mathrm{C}$ moiety (see more in Supplementary Figs. 37-38). The lowest reaction energy barrier of MN2C in ORR than that of other main group metal cofactors while closed to that of $\mathrm{Pt}$, makes it reasonable excellent performance.

\section{Discussion}

In summary, we report, for the first time, a high-performance Mg-based electrocatalyst with a super high ORR activity surpassing that of the commercial $\mathrm{Pt} / \mathrm{C}$ in alkaline electrolyte and being comparable to that in acidic condition. It changes our common knowledge of catalytic properties of main group metalsbased materials. DFT calculations reveal that a higher p-state location is generated as a $\mathrm{Mg}$ center is coordinated with two nitrogen atoms in the graphene matrix compared to other coordination numbers, which weakens the oxygenated species binding strength at $\mathrm{Mg}$ atom and leads to an ORR activity near the top of volcano-type activity plots. This study indicates that the rational materials design can help to fabricate highly active electrocatalysts based on main group metals, which may shed light on further development of catalysts.

\section{Methods}

Pre-doped graphene-based $\mathbf{N}$-coordinated $\mathbf{M g}$ cofactors. Mg-based MOFs: $[\mathrm{Mg}$ $\left.\left(\mathrm{H}_{2} \mathrm{O}\right)_{6}\right] \mathrm{Cl}_{2} \cdot 2\left[\left(\mathrm{CH}_{2}\right)_{6} \mathrm{~N}_{4}\right] \cdot 4 \mathrm{H}_{2} \mathrm{O}$ is prepared as follows. The samples are synthesized in water-alcohol mixed solution (ratio $=1: 2$ ) at room temperature (about $28^{\circ} \mathrm{C}$ ). Briefly, the $7.14 \mathrm{mM} \mathrm{MgCl} \cdot 6 \mathrm{H}_{2} \mathrm{O}$ and $3.57 \mathrm{mM}$ hexamethylenetetramine are dissolved into the mixed solution $(10 \mathrm{ml}$ alcohol and $5 \mathrm{ml}$ water) separately and then the solutions are mixed together. After magnetic stirring the liquid at room temperature for half an hour, snowflake-like solid is precipitated. The precipitate is dried in the oven at $80^{\circ} \mathrm{C}$ for overnight and the final product is obtained, denoted as $\mathrm{Mg}$-HMT.

$\mathrm{Mg}-\mathrm{N}-\mathrm{C}$ is prepared as follows. $\mathrm{Mg}-\mathrm{HMT}$ is pyrolyzed in heat treatment at $900^{\circ} \mathrm{C}$ under Ar atmosphere for $1 \mathrm{~h}$ with heating rate of $5^{\circ} \mathrm{C} \mathrm{min}{ }^{-1}$. The pyrolysis product is gray fragile bulky grains, ground by the grinding bowl. In order to get rid of the impurities, the product is then pickled in $3 \mathrm{M} \mathrm{HCl}$ aqueous solution and washed with water and ethanol (the effect from acid treatment is discussed in section 2.2 in Supplementary Information). After drying, black $\mathrm{Mg}-\mathrm{N}-\mathrm{C}$ powder is obtained. It should be noted that appropriate drying for the precursor is crucial 
before and during the pyrolysis process. The product will turn into tiny black particles after being ground, otherwise, graphite (002) strong peak will exist in the XRD pattern of $\mathrm{Mg}-\mathrm{N}-\mathrm{C}$ products if the material is not fully ground as can be seen in Supplementary Fig. 18.

The synthesis process of $\mathrm{Al}-\mathrm{HMT}$ and $\mathrm{Ca}-\mathrm{HMT}$ are similar to that of the $\mathrm{Mg}$ HMT except that $\mathrm{AlCl}_{3} \cdot 6 \mathrm{H}_{2} \mathrm{O}$ and $\mathrm{Ca}\left(\mathrm{NO}_{3}\right)_{2} \cdot 6 \mathrm{H}_{2} \mathrm{O}$ are used.

For comparison, graphene- $\mathrm{N}$ is synthesized using a modified Hummers' method ${ }^{51}$ and annealed under $\mathrm{NH}_{3}$ atmosphere.

Post-doped graphene-based N-coordinated Mg cofactors. ZIF-8 based N-Cpristine is prepared as follows. $1.68 \mathrm{~g}$ hydrated $\mathrm{Zn}\left(\mathrm{NO}_{3}\right)_{2}$ and $4 \mathrm{~g} 2$ methylimidazole are dissolved into $20 \mathrm{ml}$ and $60 \mathrm{ml}$ methanol at room temperature. The two solutions are then mixed together and stirred for $1 \mathrm{~h}$. A centrifugal precipitation is obtained, denoted as ZIF-8. After pyrolysis at $900^{\circ} \mathrm{C}$ with heating rate of $5^{\circ} \mathrm{C} \min ^{-1}$ for $3 \mathrm{~h}$ under $\mathrm{N}_{2}$ atmosphere and then pickling in $3 \mathrm{M} \mathrm{HCL}, \mathrm{ZIF}-8$ is transferred into nitrogen-doped porous carbon $(\mathbf{N}-\mathbf{C}$ pristine).

Different contents of metal- $\mathrm{N}$ co-doped $\mathrm{N}-\mathrm{C}$ are prepared as follows. $50 \mathrm{mg}$ $\mathrm{N}$-C-pristine, $30 \mathrm{mg} \mathrm{MgCl}_{2} \cdot 6 \mathrm{H}_{2} \mathrm{O}$ and $100 \mathrm{mg}$ melamine are dispersed into the isopropanol-water solution by a ratio of $1: 1$. After ultrasonic dispersion for $1 \mathrm{~h}$, the mixture is stirred for $3 \mathrm{~h}$ and a centrifugation is obtained. The centrifugal product is dried at $60^{\circ} \mathrm{C}$ in the oven for at least $12 \mathrm{~h}$ and pyrolyzed at $900{ }^{\circ} \mathrm{C}$ with heating rate of $5^{\circ} \mathrm{C} \mathrm{min}^{-1}$ for $2 \mathrm{~h}$ in $\mathrm{Ar}$ atmosphere, leading to the formation of isolated single $\mathrm{Mg}$ atom anchored on nitrogen species $(\mathbf{N}-\mathbf{C}-\mathbf{1 M g})$. $\mathbf{N}-\mathbf{C}-\mathbf{0 M g}$ (also called $\mathbf{N}-\mathbf{C}-$ no metal), $\mathbf{N}-\mathbf{C}-\mathbf{3 M g}$ and $\mathbf{N}-\mathbf{C}-\mathbf{3 A l}$ are also obtained following the same procedure except that $0 \mathrm{mg} \mathrm{MgCl} \cdot 6 \mathrm{H}_{2} \mathrm{O}, 100 \mathrm{mg} \mathrm{MgCl} \cdot 6 \mathrm{H}_{2} \mathrm{O}$ and $120 \mathrm{mg}$ $\mathrm{AlCl}_{3} \cdot 6 \mathrm{H}_{2} \mathrm{O}$ (the same mole ratio with $\mathrm{Mg}$ ) are used. $\mathbf{N}-\mathbf{C}-\mathbf{3} \mathbf{M g}$-no $\mathbf{N}$ source is also synthesized by the same procedure as $\mathrm{N}-\mathrm{C}-3 \mathrm{Mg}$ except that no $\mathrm{N}$ source (melamine) is added.

Material characterization. The HRTEM (JEOL-2011) is operated at an accelerating voltage of $200 \mathrm{kV}$. The high-angle annular dark-field scanning transmission electron microscopy (HAADF-STEM) and corresponding energydispersive spectroscopy (EDS) mapping analyses are executed on JEOL JEMARF200F TEM/STEM with a spherical aberration corrector. TGA is carried out using Shimadzu-50 thermoanalyser under flowing Ar atmosphere with a heating rate of $10^{\circ} \mathrm{C} \mathrm{min}-1$. The XPS is performed on ESCALAB $250 \mathrm{X}$-ray photoelectron spectrometer using $\mathrm{Al}$ Ka radiation. The X-ray absorption near edge structure (XANES) of Mg K-edge is investigated at the BL08U1A beamline of Shanghai Synchrotron Radiation Facility (SSRF). The adsorption curves are treated by normalized process.

Electrochemical measurements. Due to the large scale of the catalyst, full grinding is treated before test. ORR measurements are carried out using conventional rotating disk method with a MSR Electrode Rotator (Pine Research Instrumentation). A glassy carbon (GC) electrode (diameter of $5 \mathrm{~mm}$ with surface area of $\left.0.196 \mathrm{~cm}^{2}\right)$ is used as a working electrode. Au plate $\left(1 \mathrm{~cm}^{*} 1 \mathrm{~cm}\right)$ is utilized as the counter electrode in alkaline condition, instead of Pt to prevent pollution from longtime electrochemical corrosion, and graphite rod is used in acidic media. There is no change for initial ORR performance from different counter electrodes used in test is shown in Supplementary Fig. S28. The potential is recorded using $\mathrm{Ag} / \mathrm{AgCl}$ $(3.5 \mathrm{M} \mathrm{KCl})$ electrode as the reference electrode. All of the potentials are converted to the reversible hydrogen electrode (RHE) according to equation: $\mathrm{E}$ (vs. RHE) $=\mathrm{E}$ (vs. $\mathrm{Ag} / \mathrm{AgCl})+0.198 \mathrm{~V}+0.059 \times \mathrm{pH}$.

In $0.1 \mathrm{M} \mathrm{KOH}$ solution, the loading amount of $\mathrm{Mg}-\mathrm{N}-\mathrm{C}$ and $\mathrm{N}-\mathrm{C}$ is $0.4 \mathrm{mg} / \mathrm{cm}^{2}$. Four milligrams of catalyst and $30 \mu \mathrm{L}$ Nafion solution (Sigma Aldrich, $5 \mathrm{wt} \%$ ) were dispersed in $1 \mathrm{~mL}$ ethanol solution. Electrochemical measurements for the $\mathrm{Mg}-\mathrm{N}-\mathrm{C}$ catalyst are first conducted under $\mathrm{N}_{2}$-saturated $0.1 \mathrm{M} \mathrm{KOH}$ solution and then under $\mathrm{O}_{2}$-saturated solution. The ORR curve is acquired under oxygen-saturated conditions by subtracting the data under nitrogen-saturated conditions as a background. Electrochemical measurements are conducted from 1.2 to $0 \mathrm{~V}$ (vs. RHE) with a scanning rate of $0.005 \mathrm{~V} / \mathrm{s}$. The $\mathrm{CV}$ test is performed with a scanning rate of $0.01 \mathrm{~V} / \mathrm{s}$. The commercial $\mathrm{Pt} / \mathrm{C}$ is used as the reference material with the loading of $0.2 \mathrm{mg} / \mathrm{cm}^{2}$ with a scanning rate of $0.01 \mathrm{~V} / \mathrm{s}$. The electron transferred number $(n)$ is calculated according to the Koutecty-Levich (K-L) plots linear fit lines from the K-L equation:

$$
\begin{aligned}
& \frac{1}{J}=\frac{1}{J_{\mathrm{K}}}+\frac{1}{J_{\mathrm{L}}}=\frac{1}{J_{\mathrm{K}}}+\frac{1}{B W^{\frac{1}{2}}} \\
& B=0.62 \mathrm{nFC} C_{0} D_{0}^{2 / 3} V_{0}^{-1 / 6}
\end{aligned}
$$

where $J$ is the measured current density, $J_{\mathrm{K}}$ and $J_{\mathrm{L}}$ are the kinetic- and diffusion limiting current density, $\omega$ is the angular velocity, $\mathrm{n}$ is transferred electron number, $\mathrm{F}$ is the Faraday constant $\left(96485 \mathrm{C} \mathrm{mol}^{-1}\right), \mathrm{D}_{0}$ is the diffusion coefficient of $\mathrm{O}_{2}(1.9 \times$ $\left.10^{-5} \mathrm{~cm}^{2} \mathrm{~s}^{-1}\right), \mathrm{C}_{0}$ is the bulk concentration of $\mathrm{O}_{2}\left(1.2 \times 10^{-6} \mathrm{~mol} \mathrm{~cm}^{-3}\right)$ and $\mathrm{V}$ is the kinematic viscosity of the electrolyte $\left(0.01 \mathrm{~cm}^{2} \mathrm{~s}^{-1}\right)$.
The hydrogen peroxide yield $\left(\mathrm{H}_{2} \mathrm{O}_{2} \%\right)$ and the electron-transfer number (n) are calculated using the following equations:

$$
\begin{gathered}
\mathrm{H}_{2} \mathrm{O}_{2}(\%)=200 \times \frac{\frac{I_{\mathrm{R}}}{\mathrm{N}}}{I_{\mathrm{D}}+\frac{I_{\mathrm{R}}}{\mathrm{N}}} \\
n=4 \times \frac{I_{\mathrm{D}}}{\frac{I_{\mathrm{R}}}{\mathrm{N}}+I_{\mathrm{D}}}
\end{gathered}
$$

where $I_{\mathrm{D}}$ is the disk current, $I_{\mathrm{R}}$ is the ring current, and $\mathrm{N}$ is the ring collection efficiency with a value of 0.4

In $0.1 \mathrm{M} \mathrm{HClO}_{4}$, the loading amount of $\mathrm{Mg}-\mathrm{N}-\mathrm{C}$ and N-C catalysts is $0.6 \mathrm{mg}$ / $\mathrm{cm}^{2}$ and is $0.2 \mathrm{mg} / \mathrm{cm}^{2}$ for $\mathrm{Pt} / \mathrm{C}$. Electrochemical measurements are conducted from 1.2 to $0 \mathrm{~V}$ (vs. RHE) with a scanning rate of $0.01 \mathrm{~V} / \mathrm{s}$. Poison test is carried out by adding $\mathrm{KBr}, \mathrm{KCl}, \mathrm{K}_{2} \mathrm{SO}_{4}$, and $\mathrm{KSCN}$ into the solution with same mole quantities $(10 \mathrm{mM})$

The ESCA value is calculated by the equation: $\mathrm{ECSA}=\frac{C_{\mathrm{dl}}}{C_{\mathrm{s}}}$

Where $C_{\mathrm{dl}}$ is the value of electrochemical double layer capacitance. The ECSA is measured on the same working electrode and electrolyte $(0.1 \mathrm{M} \mathrm{KOH})$. The potential window of CVs was $1-1.1 \mathrm{~V}$ vs. RHE, and the scan rates are 5, 10, 15, 20, and $25 \mathrm{mV} / \mathrm{s}$. The $C_{\mathrm{dl}}$ is estimated by plotting the $\Delta \mathrm{j}$ at $1.05 \mathrm{~V}$ vs. RHE against the scan rate. The slope is twice of $C_{\mathrm{dl}}$. Note that the ECSA calculated from the $H_{\text {upd }}$ is suitable for the precious metal catalysts but is not reasonable for carbon-based catalysts for the corresponding ECSA usually include the area of carbon which is not the intrinsic active sites ${ }^{52,53}$. So $C_{\mathrm{dl}}$ is used to represent the ECSA and is shown in Supplementary Fig. S29a.

Due to the ECSA value from this method is inaccurate (always much higher than real reaction active sites) caused from extra carbon active sites, the standardized current density from ECSA $\left(j_{\mathrm{ECSA}}=\frac{j}{A_{\mathrm{ECSA}}}\right)$ is underestimated, so we only the standardized current density from geometric area $\left(j_{\text {Geom }}=\frac{j}{A_{\text {Geom }}}\right)$ to evaluate the performance of catalysts.

Zinc-air battery tests. A home-made zinc-air battery device is designed for the performance and stability test. $6 \mathrm{M} \mathrm{KOH}$ is the electrolyte while the polished zinc plate is used as the anode. $\mathrm{Mg}-\mathrm{N}-\mathrm{C}$ catalyst ink is brushed onto a $1 \mathrm{~cm}^{2}$ carbon onto $1 \mathrm{~cm}^{2}$ carbon paper (HCP030) as cathode. $20 \mathrm{wt} \% \mathrm{Pt} / \mathrm{C}$ and Graphene-N $(\mathrm{N}-\mathrm{C})$ catalysts are also prepared following the same procedure.

The electrolyte used in the primary zinc-air battery is $6 \mathrm{M} \mathrm{KOH}$. A polished zinc plate was used as the anode and a certain volume of $\mathrm{Mg}-\mathrm{N}-\mathrm{C}$ catalyst ink is brushed onto $1 \mathrm{~cm}^{2}$ carbon paper (HCP030) as cathode with a catalyst loading of 2 $\mathrm{mg} \mathrm{cm}{ }^{-2}$. As reference materials, $20 \mathrm{wt} \% \mathrm{Pt} / \mathrm{C}$ and Graphene-N (N-C) catalysts were also prepared with the same procedure and loading amount.

DFT calculation. All the DFT calculations are performed using the Vienna Ab Initio Simulation Package (VASP). The exchange-correlation potential is described by the generalized gradient approximation (GGA) with spin polarized Perdew-Burke-Ernzerhof (PBE) functional. The projector augmented wave is applied to describe the electron-ion interaction and the plane-wave energy cutoff is set to $400 \mathrm{eV}$. All structures are optimized with a convergence criterion of $1 \times 10^{-5}$ $\mathrm{eV}$ for the energy and $0.01 \mathrm{eV} / \AA$ for the forces. A periodic $4 \times 4$ graphene support is built. The vacuum spacing is set to more than $15 \AA$ for surface isolation to prevent interaction between two neighboring surfaces. Brillouin zone sampling is employed using a Monkhorst-Packing grid with $9 \times 9 \times 1$ for the calculated models Denser k-points $(9 \times 9 \times 1)$ are used for the calculations of density of states (DOS). For commercial $\mathrm{Pt} / \mathrm{C}$, we use a $\mathrm{Pt}(3 \times 3)$ unit cell of $\mathrm{Pt}(111)$ surface models. The Pt (111) slab has 4 atom layers and the top two layers are fully relaxed during the structural optimization and geometry optimizations for Pt (111) are performed with $4 \times 4 \times 1 \mathrm{k}$-mesh.

The ORR pathways on metal cofactors systems were calculated in detail according to the electrochemical framework developed by Nørskov and his coworkers ${ }^{54}$. For ORR, in an alkaline electrolyte, $\mathrm{H}_{2} \mathrm{O}$ rather than $\mathrm{H}_{3} \mathrm{O}^{+}$may act as the proton donor, so overall reaction scheme of the ORR can be written as:

$$
\mathrm{O}_{2}+2 \mathrm{H}_{2} \mathrm{O}+4 \mathrm{e}^{-} \leftrightarrow 4 \mathrm{OH}^{-}
$$

The ORR may proceed through the following elementary steps which are usually employed to investigate the electrocatalysis of the ORR on various materials:

Therefore, we took reactions (1)-(4) to derive the thermochemistry for ORR.

$$
\begin{gathered}
\mathrm{O}_{2}(\mathrm{~g})+\mathrm{H}_{2} \mathrm{O}(\mathrm{l})+\mathrm{e}^{-}+* \rightarrow \mathrm{OOH}^{*}+\mathrm{OH}^{-} \\
\mathrm{OOH}^{*}+\mathrm{e}^{-} \rightarrow \mathrm{O}^{*}+\mathrm{OH}^{-} \\
\mathrm{O}^{*}+\mathrm{H}_{2} \mathrm{O}(\mathrm{l})+\mathrm{e}^{-} \rightarrow \mathrm{OH}^{*}+\mathrm{OH}^{-} \\
\mathrm{OH}^{*}+\mathrm{e}^{-} \rightarrow *+\mathrm{OH}^{-}
\end{gathered}
$$

where * stands for an active site on the catalytic surface, (l) and (g) refer to liquid and gas phases, respectively. 
The reversible hydrogen electrode (RHE) model developed by Nørskov and coworkers was used to obtain Gibbs reaction free energy of these electrochemical elementary steps. In this model, we set up RHE as the reference electrode, which allows us to replace chemical potential $(\mu)$ of proton-electron pair with that of half a hydrogen molecule:

$$
\mu_{\mathrm{H}^{+}}+\mu_{\mathrm{e}^{-}}=\frac{1}{2} \mu_{\mathrm{H}_{2}}
$$

at conditions with $\mathrm{U}=0 \mathrm{~V}$ and $P_{\mathrm{H}_{2}}=1$ bar.

The chemical potential of each adsorbate is defined as:

$$
\mu=E+E_{\mathrm{ZPE}}-T S
$$

where the $E$ is the total energy obtained from DFT calculations, $E_{\mathrm{ZPE}}$ is zero-point energy and $S$ is the entropy at $298 \mathrm{~K}$.

Since it is difficult to obtain the exact free energy of $\mathrm{OOH}, \mathrm{O}, \mathrm{OH}$ radicals in the electrolyte solution, the adsorption free energy $\Delta G_{\mathrm{OOH}^{*}}, \Delta G_{\mathrm{O}^{*}}$ and $\Delta G_{\mathrm{OH}^{*}}$ are relative to the free energy of stoichiometrically appropriate amounts of $\mathrm{H}_{2} \mathrm{O}(\mathrm{g})$ and $\mathrm{H}_{2}(\mathrm{~g})$, defined as follows:

$$
\begin{aligned}
& \Delta G_{\mathrm{OOH}^{*}}= \Delta G\left(2 \mathrm{H}_{2} \mathrm{O}(\mathrm{g})+* \rightarrow \mathrm{OOH}^{*}+\frac{3}{2} \mathrm{H}_{2}(\mathrm{~g})\right) \\
&=\left(E_{\mathrm{OOH}^{*}}+1.5 \times E_{\mathrm{H}_{2}}-2 \times E_{\mathrm{H}_{2} \mathrm{O}}-E^{*}\right) \\
&+\left(E_{\mathrm{ZPE}}(\mathrm{OOH} *)+1.5 \times E_{\mathrm{ZPE}}\left(\mathrm{H}_{2}\right)-2 \times E_{\mathrm{ZPE}}\left(\mathrm{H}_{2} \mathrm{O}\right)-E_{\mathrm{ZPE}}(*)\right) \\
&-T \times\left(S_{\mathrm{OOH}^{*}}+1.5 \times S_{\mathrm{H}_{2}}-2 \times S_{\mathrm{H}_{2} \mathrm{O}}-S_{*}\right) \\
& \Delta G_{\mathrm{O}^{*}}= \Delta G\left(\mathrm{H}_{2} \mathrm{O}(\mathrm{g})+* \rightarrow \mathrm{O}^{*}+\mathrm{H}_{2}(\mathrm{~g})\right) \\
&=\left(E_{\mathrm{O}^{*}}+E_{\mathrm{H}_{2}}-E_{\mathrm{H}_{2} \mathrm{O}}-E^{*}\right) \\
& \quad\left(E_{\mathrm{ZPE}}(\mathrm{O} *)+E_{\mathrm{ZPE}}\left(\mathrm{H}_{2}\right)-E_{\mathrm{ZPE}}\left(\mathrm{H}_{2} \mathrm{O}\right)-E_{\mathrm{ZPE}}(*)\right)-T \\
& \quad \times\left(S_{\mathrm{OOH}^{*}}+S_{\mathrm{H}_{2}}-S_{\mathrm{H}_{2} \mathrm{O}}-S_{*}\right) \\
& \Delta G_{\mathrm{OH}^{*}}=\Delta G\left(\mathrm{H}_{2} \mathrm{O}(\mathrm{g})+* \rightarrow \mathrm{OH}^{*}+\frac{1}{2} \mathrm{H}_{2}(\mathrm{~g})\right) \\
&=\left(E_{\mathrm{OH}^{*}}+0.5 \times E_{\mathrm{H}_{2}}-E_{\mathrm{H}_{2} \mathrm{O}}-E^{*}\right) \\
&+\left(E_{\mathrm{ZPE}}(\mathrm{OOH} *)+0.5 \times E_{\mathrm{ZPE}}\left(\mathrm{H}_{2}\right)-E_{\mathrm{ZPE}}\left(\mathrm{H}_{2} \mathrm{O}\right)-E_{\mathrm{ZPE}}(*)\right)-T \\
& \times\left(S_{\mathrm{OOH}^{*}}+0.5 \times S_{\mathrm{H}_{2}}-S_{\mathrm{H}_{2} \mathrm{O}}-S_{*}\right)
\end{aligned}
$$

For each elementary step, the Gibbs reaction free energy $\Delta G$ is defined as the difference between free energies of the initial and final states and is given by the expression:

$$
\Delta G=\Delta E+\Delta \mathrm{ZPE}-T \Delta S+\Delta G_{\mathrm{U}}+\Delta G_{\mathrm{PH}}
$$

where $\Delta E$ is the reaction energy of reactant and product molecules adsorbed on catalyst surface, obtained from DFT calculations; $\Delta \mathrm{ZPE}$ and $\Delta S$ are the change in zero point energies and entropy due to the reaction. $\Delta G_{U}=-n e U$, where $U$ is the electrode applied potential relative to RHE as mentioned above, $e$ is the elementary charge transferred and $n$ is the number of proton-electron pairs transferred. $\Delta G_{\mathrm{PH}}$ is the correction of the $\mathrm{H}^{+}$free energy $\Delta G_{\mathrm{PH}}=-\mathrm{k}_{\mathrm{B}} \operatorname{Tln}\left[\mathrm{H}^{+}\right]=\mathrm{pH} \times \mathrm{k}_{\mathrm{B}} \operatorname{Tln} 10$. Hence, the equilibrium potential $\mathrm{U}_{0}$ for four-electron transfer ORR at $\mathrm{pH}=14$ was determined to be $0.402 \mathrm{~V}$ vs NHE or $1.23 \mathrm{~V}$ vs RHE according to Nernst equation: $\left.E=E_{0}-0.0591 \mathrm{pH}, U_{0}(\mathrm{RHE})=U_{0}(\mathrm{NHE})+0.828 \mathrm{~V}=0.402+0.828=1.23 \mathrm{~V}\right)$, where the reactant and product are at the same energy level. Due to the difficulty to describe the oxygen molecule with high-spin ground state, the free energy of the $\mathrm{O}_{2}$ molecule was derived according to:

$$
G_{\mathrm{O}^{2}}(\mathrm{~g})=2 G_{\mathrm{H}_{2} \mathrm{O}}(l)-2 G_{\mathrm{H}_{2}}+4 \times 1.23(\mathrm{eV})
$$

The reaction free energy of (1)-(4) for ORR can be calculated using the following equations:

$$
\begin{aligned}
& \Delta G_{1}=\Delta G_{\mathrm{OOH}^{*}}-4.92 \\
& \Delta G_{2}=\Delta G_{\mathrm{O}^{*}}-\Delta G_{\mathrm{OOH}^{*}} \\
& \Delta G_{3}=\Delta G_{\mathrm{OH}^{*}}-\Delta G_{\mathrm{O}^{*}} \\
& \Delta G_{4}=-\Delta G_{\mathrm{OH}^{*}}
\end{aligned}
$$

The onset potential is calculated by:

$$
U_{\mathrm{RHE}}^{\text {onset }}=-\max \left\{\Delta G_{1}, \Delta G_{2}, \Delta G_{3}, \Delta G_{4}\right\}
$$

In this paper, we focus on the adsorbates strength on alkaline condition. The free energy of elementary step in acidic condition can be transform by the Nernst equation, but it doesn't affect the trend of adsorbates strength on metal sites.

The over potential $\varnothing$ (V vs. RHE) in ORR test is calculated by:

$$
\varnothing=1.23-U_{\mathrm{RHE}}^{\mathrm{onset}} \text {. }
$$

The higher value of $U_{\mathrm{RHE}}^{\text {onset }}$ is, the lower value of $\varnothing$ is, and thus better predicted ORR activity is.
The volcano map and volcano plot: They are visible predictions about the trend of reaction activity. In this manuscript, based on the difference of adsorption strength at kinds of metal sites, we calculated the relationship between intermediates adsorption $\left(\Delta G_{\mathrm{OOH}}, \Delta G_{\mathrm{O}^{*}}\right.$ and $\left.\Delta G_{\mathrm{OH}^{*}}\right)$, linear relationship can be fitted by:

$$
\begin{gathered}
\Delta G_{\mathrm{OOH} *}=1.008 \times \Delta G_{\mathrm{OH} *}+3.444\left(R^{2}=0.997\right) \\
\Delta G_{\mathrm{O}^{*}}=0.94 \times \Delta G_{\mathrm{OH} *}+2.606\left(R^{2}=0.977\right)
\end{gathered}
$$

The onset potentials for each model is correlated with the free energy of intermediates adsorption, which can be calculated by:

For ORR, the onset potential is calculated by:

$$
U_{\mathrm{RHE}}^{\text {onset }}=-\max \left\{\Delta G_{1}, \Delta G_{2}, \Delta G_{3}, \Delta G_{4}\right\}
$$

where $\Delta G_{1}, \Delta G_{2}, \Delta G_{3}, \Delta G_{4}$ are the free energies of reaction barriers of each elementary steps, and calculated by:

$$
\begin{aligned}
& \Delta G_{1}=\Delta G_{\mathrm{OOH}^{*}}-4.92 \\
& \Delta G_{2}=\Delta G_{\mathrm{O}^{*}}-\Delta G_{\mathrm{OOH}^{*}} \\
& \Delta G_{3}=\Delta G_{\mathrm{OH}^{*}}-\Delta G_{\mathrm{O}^{*}} \\
& \Delta G_{4}=-\Delta G_{\mathrm{OH}^{*}}
\end{aligned}
$$

Therefore, the free energy of elementary steps and theoretical activity can be transformed to be the $\Delta G_{\mathrm{OH}^{*}-\text { related quantities. }}$

With these equations, volcano plot can be drawn.

For volcano map, the free energy of elementary steps and theoretical activity can be transformed to be the variables related to $\Delta G_{\mathrm{OOH}^{*}}$ and $\Delta G_{\mathrm{OH}^{*}}$, and a threedimensional volcano map is drawn. And the date dots represented the main group metal cofactors are located at the projection of volcano map.

The definition of p-band center of metal atoms in cofactors: For the calculation of the band center of metal atoms projected on sum of the p-orbital of metal atom, the following expression is used:

$$
\varepsilon_{\mathrm{p}}=\frac{\int_{-\infty}^{+\infty} E \times \rho_{P} d E}{\int_{-\infty}^{+\infty} \rho_{P} d E}
$$

where $\rho_{p}$ is the density of p-state projected onto metal-atom.

\section{Data availability}

The data that support the findings of this study are available from the corresponding author upon reasonable request.

Received: 8 July 2019; Accepted: 13 January 2020; Published online: 18 February 2020

\section{References}

1. Seh, Z. W. et al. Combining theory and experiment in electrocatalysis: Insights into materials design. Science 355, eaad4998 (2017)

2. Jiao, Y., Zheng, Y., Jaroniec, M. \& Qiao, S. Z. Design of electrocatalysts for oxygen-and hydrogen-involving energy conversion reactions. Chem. Soc. Rev. 44, 2060-2086 (2015)

3. Debe, M. K. Electrocatalyst approaches and challenges for automotive fuel cells. Nature 486, 43 (2012).

4. $\mathrm{Bu}, \mathrm{L}$. et al. Biaxially strained $\mathrm{PtPb} / \mathrm{Pt}$ core/shell nanoplate boosts oxygen reduction catalysis. Science 354, 1410-1414 (2016).

5. Li, M. et al. Ultrafine jagged platinum nanowires enable ultrahigh mass activity for the oxygen reduction reaction. Science 354, 1414-1419 (2016)

6. Zheng, Y. et al. Molecule-level g-C3N4 coordinated transition metals as a new class of electrocatalysts for oxygen electrode reactions. J. Am. Chem. Soc. 139, 3336-3339 (2017)

7. Hammer, B. \& Nørskov, J. K. In Advances in Catalysis, vol. 45, 71-129 (Academic Press, 2000).

8. Greeley, J. et al. Alloys of platinum and early transition metals as oxygen reduction electrocatalysts. Nat. Chem. 1, 552-556 (2009).

9. Shao, M., Liu, P., Zhang, J. \& Adzic, R. Origin of enhanced activity in palladium alloy electrocatalysts for oxygen reduction reaction. J. Phys. Chem. B 111, 6772-6775 (2007).

10. Xu, H., Cheng, D., Cao, D. \& Zeng, X. C. A universal principle for a rational design of single-atom electrocatalysts. Nat. Catal. 1, 339-348 (2018).

11. Lundqvist, B. I., Gunnarsson, O., Hjelmberg, H. \& Nørskov, J. K. Theoretical description of molecule-metal interaction and surface reactions. Surf. Sci. $\mathbf{8 9}$ 196-225 (1979).

12. Hammer, B. \& Norskov, J. K. Why gold is the noblest of all the metals. Nature 376, 238 (1995) 
13. Stamenkovic, V. R. et al. Improved oxygen reduction activity on Pt3Ni(111) via increased surface site availability. Science 315, 493-497 (2007).

14. Zhu, B., Qiu, K., Shang, C. \& Guo, Z. Naturally derived porous carbon with selective metal-and/or nitrogen-doping for efficient $\mathrm{CO} 2$ capture and oxygen reduction. J. Mater. Chem. A 3, 5212-5222 (2015).

15. Légaré, M.-A. et al. Nitrogen fixation and reduction at boron. Science $\mathbf{3 5 9}$, 896-900 (2018).

16. Cowan, J. A. Structural and catalytic chemistry of magnesium-dependent enzymes. Biometals 15, 225-235 (2002).

17. Dunn, M. F., Ramírez-Trujillo, J. A. \& Hernández-Lucas, I. Major roles of isocitrate lyase and malate synthase in bacterial and fungal pathogenesis. Microbiology 155, 3166-3175 (2009).

18. Sissi, C. \& Palumbo, M. Effects of magnesium and related divalent metal ions in topoisomerase structure and function. Nucleic Acids Res. 37, 702-711 (2009).

19. Yean, S.-L., Wuenschell, G., Termini, J. \& Lin, R.-J. Metal-ion coordination by U6 small nuclear RNA contributes to catalysis in the spliceosome. Nature 408, 881-884 (2000).

20. Calle-Vallejo, F., Martínez, J. I., García-Lastra, J. M., Abad, E. \& Koper, M. T. M. Oxygen reduction and evolution at single-metal active sites: Comparison between functionalized graphitic materials and protoporphyrins. Surf. Sci. 607, 47-53 (2013).

21. Yu, Y., Cui, C., Wang, J. \& Lu, Y. Biosynthetic approach to modeling and understanding metalloproteins using unnatural amino acids. Science China. Chemistry 60, 188-200 (2017).

22. Calle-Vallejo, F., Martinez, J. I. \& Rossmeisl, J. Density functional studies of functionalized graphitic materials with late transition metals for oxygen reduction reactions. Phys. Chem. Chem. Phys. 13, 15639-15643 (2011).

23. Edwards, W. D. \& Zerner, M. C. Electronic structure of model chlorophyll systems. Int. J. Quantum Chem. 23, 1407-1432 (1983).

24. Levitt, L. S. Mg-N bond length in chlorophyll. J. Chem. Phys. 28, 515-516 (1958).

25. Rosa, A. \& Baerends, E. J. Metal-macrocycle interaction in phthalocyanines: density functional calculations of ground and excited states. Inorg. Chem. 33, 584-595 (1994).

26. Zhu, G., Li, Y., Lü, K. \& Sun, Q. Phthalocyanine-based organometallic nanocages: properties and gas storage. ChemPhysChem 15, 126-131 (2014).

27. Lin, C.-Y., Zhang, L., Zhao, Z. \& Xia, Z. Design principles for covalent organic frameworks as efficient electrocatalysts in clean energy conversion and green oxidizer production. Adv. Mater. 29, 1606635 (2017).

28. Man, I. C. et al. Universality in oxygen evolution electrocatalysis on oxide surfaces. ChemCatChem 3, 1159-1165 (2011).

29. Kresse, G. \& Hafner, J. Ab initio molecular dynamics for open-shell transition metals. Phys. Rev. B 48, 13115 (1993).

30. Chen, $\mathrm{Y}$. et al. Isolated single iron atoms anchored on $\mathrm{N}$-doped porous carbon as an efficient electrocatalyst for the oxygen reduction reaction. Angew. Chem. 129, 7041-7045 (2017)

31. Koper, M. T. M. Thermodynamic theory of multi-electron transfer reactions: Implications for electrocatalysis. J. Electroanalytical Chem. 660, 254-260 (2011).

32. Rossmeisl, J., Qu, Z.-W., Zhu, H., Kroes, G.-J. \& Nørskov, J. K. Electrolysis of water on oxide surfaces. J. Electroanalytical Chem. 607, 83-89 (2007).

33. Hong, W. T. et al. Toward the rational design of non-precious transition metal oxides for oxygen electrocatalysis. Energy Environ. Sci. 8, 1404-1427 (2015).

34. NEWNS, D. M. Self-consistent model of hydrogen chemisorption. Phys. Rev. 178, 1123-1135 (1969).

35. Vojvodic, A., Nørskov, J. K. \& Abild-Pedersen, F. Electronic structure effects in transition metal surface chemistry. Top. Catal. 57, 25-32 (2014).

36. Koper, M. T. M. \& van Santen, R. A. Interaction of $\mathrm{H}, \mathrm{O}$ and $\mathrm{OH}$ with metal surfaces. J. Electroanalytical Chem. 472, 126-136 (1999).

37. Luther Iii, G. W. Kinetics of the reactions of water, hydroxide ion and sulfide species with $\mathrm{CO}_{2}$, OCS and $\mathrm{CS}_{2}$ : frontier molecular orbital considerations. Aquat. Geochem. 10, 81-97 (2004).

38. Deng, D. et al. A single iron site confined in a graphene matrix for the catalytic oxidation of benzene at room temperature. Sci. Adv. 1, e1500462 (2015).

39. Yang, Y. et al. O-, N-Atoms-coordinated Mn cofactors within a graphene framework as bioinspired oxygen reduction reaction electrocatalysts. $A d v$. Mater. 30, 1801732 (2018).

40. Bezerra, C. W. et al. A review of heat-treatment effects on activity and stability of PEM fuel cell catalysts for oxygen reduction reaction. J. Power Sources 173, 891-908 (2007).

41. Li, W., Yu, A., Higgins, D. C., Llanos, B. G. \& Chen, Z. Biologically inspired highly durable iron phthalocyanine catalysts for oxygen reduction reaction in polymer electrolyte membrane fuel cells. J. Am. Chem. Soc. 132, 17056-17058 (2010).
42. Gordon, L. M. et al. Amorphous intergranular phases control the properties of rodent tooth enamel. Science 347, 746-750 (2015).

43. Ildefonse, P., Calas, G., Flank, A. M. \& Lagarde, P. Low Z elements $(\mathrm{Mg}, \mathrm{Al}$, and $\mathrm{Si}) \mathrm{K}$-edge $\mathrm{X}$-ray absorption spectroscopy in minerals and disordered systems. Nucl. Instrum. Methods Phys. Res. Sect. B: Beam Interact. Mater. At. 97, 172-175 (1995).

44. Yoshimura, T. et al. Magnesium K-edge XANES spectroscopy of geological standards. J. synchrotron Radiat. 20, 734-740 (2013).

45. $\mathrm{Hu}, \mathrm{X}$. et al. Two-dimensional covalent organic frameworks as self-template derived nitrogen-doped carbon nanosheets for eco-friendly metal-free catalysis. Appl. Catal. B: Environ. 244, 25-35 (2019).

46. Jiao, Y., Zheng, Y., Jaroniec, M. \& Qiao, S. Z. Origin of the electrocatalytic oxygen reduction activity of graphene-based catalysts: a roadmap to achieve the best performance. J. Am. Chem. Soc. 136, 4394-4403 (2014).

47. Oh, I., Biggin, M. E. \& Gewirth, A. A. Poisoning the active site of electrochemical reduction of dioxygen on metal monolayer modified electrode surfaces. Langmuir 16, 1397-1406 (2000).

48. Cheng, Y., Zhang, J. \& Jiang, S. P. Are metal-free pristine carbon nanotubes electrocatalytically active? Chem. Commun. 51, 13764-13767 (2015).

49. Thorum, M. S., Hankett, J. M. \& Gewirth, A. A. Poisoning the oxygen reduction reaction on carbon-supported $\mathrm{Fe}$ and $\mathrm{Cu}$ electrocatalysts: evidence for metal-centered activity. J. Phys. Chem. Lett. 2, 295-298 (2011).

50. Fei, H. et al. General synthesis and definitive structural identification of MN4C4 single-atom catalysts with tunable electrocatalytic activities. Nature. Catalysis 1, 63-72 (2018).

51. Hummers, W. S. Jr \& Offeman, R. E. Preparation of graphitic oxide. J. Am. Chem. Soc. 80, 1339-1339 (1958)

52. Wu, G., More, K. L., Johnston, C. M. \& Zelenay, P. High-performance electrocatalysts for oxygen reduction derived from polyaniline, iron, and cobalt. Science 332, 443-447 (2011).

53. Li, Z. et al. Ionic liquids as precursors for efficient mesoporous iron-nitrogendoped oxygen reduction electrocatalysts. Angew. Chem. Int. Ed. 54, 1494-1498 (2015).

54. Nørskov, J. K. et al. Origin of the overpotential for oxygen reduction at a fuelcell cathode. J. Phys. Chem. B 108, 17886-17892 (2004).

\section{Acknowledgements}

This study was supported by the National Natural Science Foundation (51772283), the National Key R\&D Program of China (Grant No. 2016YFA0401801) and Fundamental Research Funds for the Central Universities (WK2060140021). The calculations were completed on the supercomputing system in the Supercomputing Center of USTC. We thank BL08U1A beam station for XANES test in Shanghai Synchrotron Radiation Facility (SSRF). We thank the soft X-ray magnetic circular dichroism end station (XMCD) of the National Synchrotron Radiation Laboratory (NSRL) for measuring $\mathrm{C}$ K-edge and $\mathrm{N}$ K-edge XANES.

\section{Author contributions}

Shuai Liu and Qianwang Chen conceived the idea, designed research and analysed the data. Shuai Liu, Zedong Li, and Changlai Wang performed the DFT calculations; Shuai Liu and Minxue Huang synthesized the catalysts and conducted the reaction tests; Ming Zuo conducted the STEM and EELS analyses; Lijuan Zhang performed the XANES analysis. Yang Yang, Yang Kang, Shi Chen, and Pengping Xu performed the structural characterization analysis. Shuai Liu, Weiwei Tao and Qianwang Chen wrote the paper.

\section{Competing interests}

The authors declare no competing interests.

\section{Additional information}

Supplementary information is available for this paper at https://doi.org/10.1038/s41467 020-14565-w.

Correspondence and requests for materials should be addressed to Q.C.

Peer review information Nature Communications thanks the anonymous reviewers for their contributions to the peer reivew of this work. Peer review reports are available.

Reprints and permission information is available at http://www.nature.com/reprints Publisher's note Springer Nature remains neutral with regard to jurisdictional claims in published maps and institutional affiliations. 
(c) (i) Open Access This article is licensed under a Creative Commons Attribution 4.0 International License, which permits use, sharing, adaptation, distribution and reproduction in any medium or format, as long as you give appropriate credit to the original author(s) and the source, provide a link to the Creative Commons license, and indicate if changes were made. The images or other third party material in this article are included in the article's Creative Commons license, unless indicated otherwise in a credit line to the material. If material is not included in the article's Creative Commons license and your intended use is not permitted by statutory regulation or exceeds the permitted use, you will need to obtain permission directly from the copyright holder. To view a copy of this license, visit http://creativecommons.org/ licenses/by/4.0/.

(C) The Author(s) 2020 